\title{
Reducing AIDS-related stigma and discrimination in Indian hospitals
}

Vaishali Sharma Mahendra

Population Council

Laelia Gilborn

Population Council

Bitra George

Luke Samson

Rupa Mudoi

See next page for additional authors

Follow this and additional works at: https://knowledgecommons.popcouncil.org/departments_sbsr-hiv

Part of the Demography, Population, and Ecology Commons, Health Policy Commons, Immune System Diseases Commons, International Public Health Commons, Medicine and Health Commons, Public Health Education and Promotion Commons, Social Policy Commons, and the Virus Diseases Commons

How does access to this work benefit you? Let us know!

\section{Recommended Citation}

Mahendra, Vaishali Sharma, Laelia Gilborn, Bitra George, Luke Samson, Rupa Mudoi, Sarita Jadav, Indrani Gupta, Shalini Bharat, and Celine Daly. 2006. "Reducing AIDS-related stigma and discrimination in Indian hospitals," Horizons Final Report. New Delhi: Population Council. 


\section{Authors}

Vaishali Sharma Mahendra, Laelia Gilborn, Bitra George, Luke Samson, Rupa Mudoi, Sarita Jadav, Indrani Gupta, Shalini Bharat, and Celine Daly 


\section{Horizons}

Reducing AIDS-related Stigma and Discrimination in Indian Hospitals
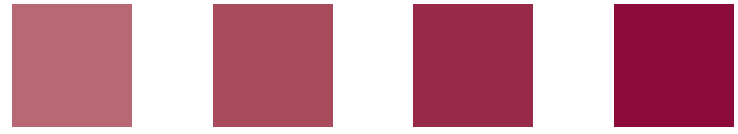

Horizons Program

Sharan

Institute of Economic Growth 


\title{
Reducing AI DS-related Stigma and Discrimination in I ndian Hospitals
}

\author{
Vaishali S. Mahendra ${ }^{1}$, Laelia Gilborn ${ }^{1}$, Bitra George ${ }^{2}$, \\ Luke Samson², Rupa Mudoi², Sarita Jadav², \\ Indrani Gupta ${ }^{3}$, Shalini Bharat ${ }^{4}$, and Celine Daly ${ }^{1}$
}

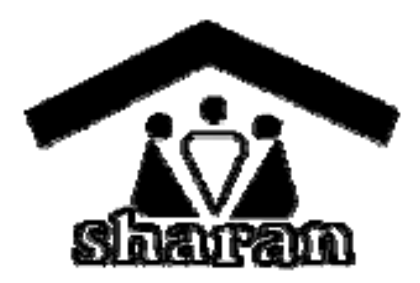

Institutional affiliations at the time of the study:

${ }^{1}$ Horizons/Population Council

${ }^{2}$ Sharan

${ }^{3}$ Institute of Economic Growth

${ }^{4}$ Consultant, Tata Institute of Social Sciences

\section{${ }^{H}$ rizons}

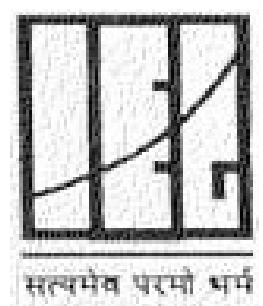

सत्यमेव परमो भर्म 
This project was funded by the Horizons Program. Horizons is implemented by the Population Council in collaboration with the International Center for Research on Women, International HIV/AIDS Alliance, PATH, Tulane University, Family Health International, and Johns Hopkins University. Horizons is funded by the President's Emergency Plan for AIDS Relief through the U.S. Agency for International Development, under the terms of HRN-A-000-97-00012-00. The opinions expressed herein are those of the authors and do not necessarily reflect the views of the U.S. Agency for International Development.

Published in April 2006.

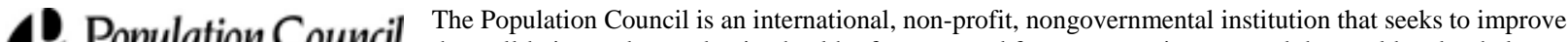 the well-being and reproductive health of current and future generations around the world and to help achieve a humane, equitable, and sustainable balance between people and resources. The Council conducts biomedical, social science, and public health research and helps build research capacities in developing countries. Established in 1952, the Council is governed by an international board of trustees. Its New York headquarters supports a global network of country offices.}

Copyright 2006 The Population Council Inc.

Suggested citation: Mahendra, V. S., L. Gilborn, B. George, L. Samson, R. Mudoi, S. Jadav, I. Gupta, S. Bharat, and C. Daly. 2006. "Reducing AIDS-related stigma and discrimination in Indian hospitals," Horizons Final Report. New Delhi.: Population Council. 



\section{Acknowledgments}

This study was a collaborative effort of a number of individuals representing three organizations: Vaishali Sharma Mahendra, Laelia Gilborn, and Celine Daly of the Horizons Program/Population Council; Bitra George, Luke Samson, Rupa Mudoi, Sarita Jadav, Arhcana Panda, and Shweta Bajaj of Sharan; and Indrani Gupta, Dev Mani Upadhyay, and Garima of the Institute for Economic Growth. In addition, the research team included the following consultants: Shalini Bharat, Venkat Raman, Rajendra Prasad, and Reena Dey.

The research team would like to thank the officials at the National AIDS Control Organization (NACO) for the support extended to the study. We wish to particularly thank Dr. P. L. Joshi, former Additional Project Director (NACO), for chairing the Project Implementation Review Committee as well as for his keen interest and technical guidance in development of tools such as the Achievement Checklist and Hospital Guidelines. Arun Baroka, DSACS, extended his support and assistance in finalizing the hospital guidelines.

We would like to acknowledge the support extended by the three participating hospitals, in particular Dr. N. Kaul, Dr. S. Salhan, Dr. C. Wattal, Dr. L. Duggal, Dr. K. Ray, Dr. D. K. Sharma, Dr. B. Sagar, Dr. T. K. Joshi, Dr. A. Nath, and Sister June Caroline, for their active role in implementing the project in their hospitals. In addition, we would like to extend our thanks to all the staff who participated as reviewers of study protocols, research respondents, and partners in the design and implementation of interventions.

We are very grateful to Isabelle de Zoysa for her inputs in designing this operations research study and in particular for contributing to the idea of the development of a checklist. In addition, we would also like to thank Venkat Raman (Faculty of Management Studies, New Delhi), for assisting us with the design and implementation of the action plans in the participating hospitals and Reena Dey (BCC consultant) for designing, pre-testing, and finalizing the IEC materials in collaboration with the hospitals. A special thanks to Neville Sellhore and the team from SAHARA and Akshay Khanna, Chinkolal Thangsing, Elizabeth Sellhore, Elizabeth Vatsyayan, Gunjan Sharma, Shantanu Choudhary and Sidharth Vatsyayan, for assisting in implementing various components of the intervention in the hospitals. Lester Coutinho, Elizabeth Cherian, and Reuben Israeal also contributed to the implementation of the study. We would like to acknowledge Rajendra Prasad, Dev Mani Upadhyaya, and Garima who provided able support and assistance with data management and analysis.

Special thanks to V. L. Thomas for his excellent administrative support throughout the study as well as expert assistance in creating the tables, graphs, and formatting the report. Special thanks are due to Ellen Weiss and Julie Pulerwitz for providing technical and editorial comments to strengthen and finalize this report. Sherry Hutchinson and Alison Lee lent their much-needed support in copyediting, formatting, and designing the report.

Most importantly, we would like to thank all the patients, their families and friends, and health care workers who participated in the research. 


\section{Table of Contents}

Executive Summary 1

I ntroduction $\quad 6$

$\begin{array}{ll}\text { Addressing AIDS-related stigma and discrimination } & 7\end{array}$

$\begin{array}{ll}\text { Study goal and objectives } & 7\end{array}$

$\begin{array}{lr}\text { Methods } & 9\end{array}$

Research setting $\quad 9$

$\begin{array}{ll}\text { Study design } & 10\end{array}$

Measures 13

$\begin{array}{ll}\text { Ethical procedures } & 16\end{array}$

$\begin{array}{ll}\text { Data management and analysis } & 16\end{array}$

Results from the Formative Research and Baseline Survey 18

Attitudes of health care workers $\quad 18$

$\begin{array}{ll}\text { Denial of care } & 19\end{array}$

HIV counseling and testing procedures $\quad 19$

Disclosure of test results and patient confidentiality 20

Use of universal precautions by health care workers $\quad 23$

Institutional support for infection control and universal precautions $\quad 24$

$\begin{array}{ll}\text { Stigmatizing attitudes and practices among health care workers } & 24\end{array}$

$\begin{array}{ll}\text { Development of the I ntervention } & 28\end{array}$

$\begin{array}{ll}\text { Intervention components } & 28\end{array}$

Results from the Assessment of the I ntervention 32

Changes in attitudes toward PLHA 32

Changes in attitudes toward discriminatory hospital practices $\quad 34$ 
Change in mean stigma scores of health care workers $\quad 35$

Changes in stigma levels of health care workers $\quad 36$

Changes in knowledge of HIV transmission 38

Changes in health care workers’ practices $\quad 39$

$\begin{array}{ll}\text { Universal precautions } & 45\end{array}$

Managers’ perspectives on the intervention process and impact $\quad 47$

Conclusions and Recommendations $\quad 50$

Utilization of Research Results and Tools 53

$\begin{array}{ll}\text { References } & 54\end{array}$

Appendix: PLHA-friendly Checklist 
Reducing AIDS-related Stigma and Discrimination in Indian Hospitals

\section{Executive Summary}

AIDS-related stigma and discrimination is a pervasive problem worldwide. People living with HIV/AIDS (PLHA) in India, as elsewhere, face stigma and discrimination in a variety of contexts, including the household, community, workplace, and health care setting. Research in India has shown that stigma and discrimination against HIV-positive people and those perceived to be infected are common in hospitals and act as barriers to seeking and receiving critical treatment and care services (UNAIDS 2001).

Recognizing the need to move beyond documentation of the problem, three New Delhi hospitals; SHARAN, an Indian NGO; and the Horizons Program, with support from the National AIDS Control Organisation (NACO), carried out an operations research project to develop and test responses to hospital-based stigma and discrimination against people living with HIV/AIDS.

The objectives of the project were to identify the strengths and limitations of existing services for HIVinfected individuals in hospitals, and to use this information to design tools and approaches for motivating hospitals to become more "PLHA-friendly" through improved policies, staff training, and services.

\section{Methods}

Researchers used a pre-/post-test evaluation design to assess the outcomes of the pilot program conducted in three hospitals in New Delhi (one private and two government-run).

Prior to the implementation of the program, formative research was conducted to understand the causes and manifestations of stigma and discrimination in health care settings. This involved conducting in-depth interviews with health care workers and HIV-positive patients and focus group discussions with people living with HIV/AIDS and NGO service providers. These findings informed the development of a "PLHA-friendly Checklist," a self-assessment tool for hospital managers to identify institutional strengths and weaknesses of services for people infected with HIV, and of hospital policies and procedures to prevent occupational exposure to HIV by staff. The Checklist covers the following areas: access to care services, HIV testing and counseling, confidentiality, infection control, and quality of care.

To assess outcomes of the program, a baseline survey to measure HIV/AIDS-related attitudes, knowledge, and practices was conducted with a random sample of 884 health care workers from four departments. These health care workers represented three levels of hospital staff that have contact with PLHA: doctors, nurses, and ward staff (i.e., those responsible for daily cleaning of patient areas). These data were discussed with hospital managers who then used the Checklist to assess the extent to which their facilities followed gold standards to ensure AIDS-related staff safety and a non-stigmatizing and nondiscriminatory hospital environment. Based on this assessment, hospital managers and senior representatives of doctors, nurses, and ward staff developed action plans to improve the situation. The project team and local AIDS service organizations helped each hospital carry out their action plans by assisting with training and the development and dissemination of policy guidelines and educational materials, such as posters on infection control. 


\section{Hgrizons}

To assess progress, the researchers administered a follow-up survey to a random sample of 885 health care workers and conducted qualitative interviews with hospital managers. As part of the baseline and endline surveys, a 21-item stigma index was included to examine health care workers' attitudes toward PLHA and discriminatory practices in the health care setting.

\section{Key Findings}

\section{Manifestations of stigma and discrimination in hospitals range from condescending attitudes to delay and denial of treatment.}

As reported by people living with HIV/AIDS and health care workers, common manifestations of stigma and discrimination in hospitals include unwarranted referrals to other facilities; condescending, judgmental, and moralistic attitudes among staff; segregation and labeling of patients; excessive use of barrier precautions by staff; unconsented HIV testing; inadequate pre- and post-test counseling; withholding of HIV test results from the patient; and unconsented disclosure of test results to family and non-treating staff.

\section{Both individual and institutional factors contribute to AIDS-related stigma and discrimination in health care settings.}

Staff prejudice against HIV-positive patients and patients considered to be at risk for HIV, staff misconceptions about HIV transmission and a resultant fear of contact with blood-borne pathogens, lack of hospital policies protecting people living with HIV/AIDS and ensuring staff safety, and inadequate training of staff on infection control contribute to differential treatment of HIV-infected clients in the study hospitals.

\section{When presented with data from their institutions, managers instituted hospital-wide initiatives to combat stigmatizing attitudes and discriminatory practices.}

Upon reviewing the baseline survey data, the managers, many of whom were previously reluctant to acknowledge problems, set and achieved action plan goals, such as establishing an HIV/AIDS care and management policy, enlisting NGOs to sensitize and train health care workers, strengthening and mainstreaming HIV counseling, and developing and disseminating information on infection control procedures and the availability of post-exposure prophylaxis to staff.

\section{Health care workers’ attitudes toward people living with HIV/AIDS improved.}

Scores on the stigma index could range from a minimum of 21 to a maximum of 63 (a higher score indicated greater stigma). Over time, the mean score on the stigma index for all health care workers had declined significantly (from 42.79 to 38.07; $\mathrm{p}<.05$ ), thus indicating an improvement in their attitudes toward PLHA and reduced support for discriminatory hospital practices. As part of the analysis, the total scores were trichotomized into three categories-low stigma (mean score 21-34), medium stigma (34- 
48), and high stigma (49-63). After the intervention, the proportion of HCWs who were categorized as being the least stigmatizing more than doubled (12 percent vs. 27 percent) and the proportion of respondents in the most stigmatizing category declined considerably (24 percent vs. 7 percent). At both points in time, the majority of HCWs fell in the moderate stigma range, thus indicating that work is still needed to address HCWs' attitudes, particularly relating to fear of contagion in the health care setting.

\section{Understanding of HIV transmission increased among health care workers.}

Overall, there were large increases in knowledge, especially among ward staff. For example, there was a significant increase $(\mathrm{p}<.05)$ in the number of ward staff who reported that HIV cannot be transmitted by touching someone with HIV/AIDS (80 percent vs. 96 percent), by sharing utensils (67 percent vs. 83 percent), by sharing clothes (63 percent vs. 86 percent), and by coming close to someone with HIV/AIDS (81 percent vs. 98 percent).

Despite improvements, some misinformation persists, particularly among ward staff. For example, at endline, only 35 percent of ward staff believed that HIV is not transmitted by mosquitoes and 51 percent that it is not transmitted through sputum.

\section{Doctors reported improvements in their HIV testing and counseling attitudes and practices.}

After the intervention, doctors were more likely to agree that patients should not be tested for HIV without their consent (37 percent vs. 67 percent; $\mathrm{p}<.05$ ). They also were more likely to seek informed consent the last time they ordered an HIV test (40 percent vs. 59 percent; $\mathrm{p}<.05$ ). An improvement in counseling practices was observed in the sub-sample of doctors who had ever received a positive test result for a patient whom they referred for an HIV test ( $n=48$ at baseline and $n=59$ at endline). At endline, a significantly $(\mathrm{p}<.05)$ greater proportion of doctors reported that they always arranged pre-test counseling (31 percent vs. 46 percent) and post-test counseling (56 percent vs. 69 percent).

\section{Although there have been some improvements in patient confidentiality, more work is needed.}

The findings were mixed regarding the importance and protection of patient confidentiality by health care workers. After the intervention, a greater proportion of doctors (74 percent vs. 85 percent; $\mathrm{p}<.05$ ) and nurses (89 percent vs. 92 percent) said that HIV-positive individuals have the right to decide who should know their status, but this was not the case among ward staff (73 percent vs. 66 percent). At baseline, health care workers often took it upon themselves to inform peers and other staff in the hospital about a patient's HIV-positive status. At follow-up there was some improvement among doctors, as a smaller proportion reported informing nurses (87 percent vs. 71 percent) and ward staff (51 percent vs. 30 percent) about a patient's serostatus. Nurses corroborated this trend; compared to baseline, a smaller proportion at follow-up reported being informed by doctors of a patient's positive HIV status (31 percent vs. 17 percent). But there was essentially no change among nurses in telling ward staff ( 97 percent vs. 99 percent); therefore they do not appear to have become more discreet at follow-up. 


\section{Hgrizons}

Understanding and practice of universal precautions and infection control improved among health care workers.

At endline, more doctors reported wearing gloves for at-risk procedures such as drawing blood (64 percent vs. 93 percent; $\mathrm{p}<.05$ ), as did ward staff for procedures such as carrying patients blood samples (29 percent vs. 93 percent; $\mathrm{p}<.05$ ). At the same time, fewer staff reported lack of supplies for universal precautions and infection control (21 percent vs. 6 percent; $\mathrm{p}<.05)$. Also, health care workers were more likely to report that they can access post-exposure prophylaxis if they have been occupationally exposed to HIV (29 percent vs. 40 percent; $\mathrm{p}<.05$ ) and less likely to report that clothes and linen used by HIVpositive patients should be disposed or burned (67 percent vs. 54 percent; $\mathrm{p}<.05$ ).

\section{Conclusions and Recommendations}

Although there was variation among the hospitals in their action plan accomplishments, overall the intervention process was associated with improvements among health care workers in HIV knowledge, attitudes toward people living with HIV/AIDS, and certain practices with respect to HIV counseling and testing and confidentiality. The following recommendations emerged from the study:

In order to reduce stigma and discrimination, it is important to assess and improve HIV/AIDS-related knowledge and attitudes of all HCWs.

Misinformation and judgmental attitudes among all cadres of HCWs can foster stigma, fear, and differential treatment of PLHA. This study showed that even the most senior HCWs do not have complete understanding of HIV transmission and prevention. Therefore, it is important for programs to target all levels of HCWs with initial and ongoing refresher training. Such training should go beyond providing information to include sensitizing staff to the needs, concerns, and rights of PLHA.

\section{Efforts to increase knowledge and improve attitudes must be accompanied by policies, information, and supplies that create a safe working environment for HCWs.}

This and other studies (Nyblade et al. 2003) have shown that health care workers perceive themselves to be at high risk of infection because of their exposure to the virus during service delivery. Thus, training alone may not have the desired impact on health care workers' attitudes and practices if they do not perceive the environment within which they work as safe to implement their newly acquired knowledge and skills. Thus it is essential to assess and acknowledge health care workers' fears and risk and then develop and implement workplace policies that ensure staff safety and respect for health care workers' rights. These policies need to ensure the availability of essential supplies (e.g., gloves, post-exposure prophylaxis) for maintaining optimum infection control practices by health care workers at all times to not only protect themselves but also protect their patients from exposure to infection. 


\section{A multi-sectoral, participatory approach to reducing stigma and discrimination is promising.}

Improvements in reported HCW attitudes and practices and in hospital policies supports an approach characterized by participatory problem identification and problem solving and the involvement of all levels of staff in intervention activities, from ward staff to hospital superintendents. Groups and organizations wishing to work in health care settings should consider positioning themselves as true partners rather than as critics if their goal is to improve the health care environment for PLHA.

\section{Further research is needed to determine whether the improvements observed reflect actual reductions in stigma and discrimination as perceived by PLHA.}

Conducting this research in Indian hospitals that now are seeing greater numbers of PLHA or in regions with a higher HIV prevalence would enable researchers to gain valuable feedback from HIV-positive patients. Also, any further research should examine the role of increased availability of antiretrovirals on stigma and discrimination in health care settings.

\section{Utilization of the Findings}

The results of the study galvanized the collaborating New Delhi hospitals to expand the program hospitalwide to all departments and staff. In addition, NACO has endorsed the use of the Checklist for use in all public hospitals and has disseminated it to all of the State AIDS Control Societies in the country. In response to requests, the Checklist, policy guidelines, and other materials have been widely distributed to NGOs and health care organizations, including the Employees State Insurance Corporation, one of the country's largest insurance based health delivery systems. 


\section{Hgrizons}

\section{Introduction}

Stigma has often been associated with disfiguring or incurable diseases, in particular, diseases that society perceives to be caused by the violation of social norms, including those that sanction sexual behavior. HIV/AIDS is a good example of this type of disease (Crandall and Moriarty 1995). A definition of stigma that has frequently been used in association with HIV/AIDS comes from a 1960s study on stigma in relation to mental illness, physical deformities, and "socially deviant" behaviors. This definition describes stigma as societal labeling of and individual or group as different or deviant because of a "discrediting attribute” (Goffman 1963). More recently, stigma has been defined as a dynamic process that is linked to competition for power and tied into existing social mechanisms of exclusion and dominance (Link and Phelan 2001). Parker and Aggleton (Horizons 2002) describe stigma as a social process that involves identifying and using "differences" between groups of people to create and legitimize social hierarchies and inequalities.

In 1987, early in the epidemic’s history, Jonathan Mann, former head of WHO’s Global Program on AIDS, identified stigma as the "third epidemic," following the hidden, yet accelerating spread of HIV infection and the visible rise in AIDS cases. He recognized that stigma, discrimination, blame, and denial were potentially the most difficult aspects of HIV/AIDS to address, but also that addressing them was key to overcoming the spread of the disease (Mann 1987).

The ramifications of AIDS-related stigma and discrimination are numerous. Fear of stigma and discrimination keeps people from learning their HIV status, and if positive, from disclosing their status to others and accessing health services. Perceived and enacted stigma can place a huge psychological burden on an infected individual and thereby contribute to a decline in health status. Stigmatizing attitudes and discriminatory practices of family members and health providers prevent those infected from receiving adequate treatment, care, and support (van der Meij and Heijnders 2004; Brown, Macintyre and Trujillo 2003; UNAIDS 2002).

While AIDS-related stigma has become better understood in the more than 20 years since the first AIDS case was diagnosed, it nevertheless remains a pervasive problem. Various studies have established that AIDS-related stigma is widespread and occurs in a variety of contexts, including the family, community, workplace, and the health care setting (Reidpath and Chan 2005; Nyblade et al. 2003; Horizons 2003; Bharat and Aggleton 1999; UNAIDS 2001).

With regard to health care settings, a UNAIDS-supported study in two Indian cities, Mumbai and Bangalore, found that people living with HIV/AIDS (PLHA) commonly experienced stigma and discrimination in hospitals, which manifested in a variety of ways. These included denial of care; widespread labeling of patients as HIV-positive; HIV testing without consent; disclosure of HIV status to family members, employers, non-treating health care workers, and other patients; and excessive use of barrier precautions for HIV-infected patients (UNAIDS 2001). More recently, an article published in 2003 in the newspaper The Hindu reported that 90 percent of doctors in the state of Tamil Nadu refused to treat PLHA. Studies by the Asia Pacific Network for Positive People (along with the Indian Network for Positive People) and Positive Women's Network (PWN+) have further documented PLHA experiences of stigma and discrimination in hospitals in the country, corroborating earlier findings (APN+ 2003; CFAR, PWN+, and UNIFEM 2003). 


\section{Addressing AI DS-related Stigma and Discrimination}

Despite the magnitude of the problem, it is only recently that responses are moving beyond documenting negative experiences to implementing interventions that specifically address stigma and discrimination. A 2002 review of interventions that attempted to explicitly reduce AIDS-related stigma in developed and developing countries concluded that it would be unrealistic to eliminate stigma, but possible to reduce it through a variety of intervention strategies. The authors also noted that most of the interventions in developing countries were community-based and not rigorously evaluated. They recommended that intervention strategies aimed at individuals in an institutional setting be developed and tested in order to address structural as well as individual determinants of stigma (Brown, Macintyre, and Trujillo 2003). Parker and Aggleton (Horizons 2002) noted that to challenge stigma and discrimination, social action is required to change the context within which individuals and communities respond to HIV/AIDS. In order to do this, individual approaches need to be complemented by actions to address environmental and structural constraints that foster AIDS-related stigma and discrimination.

Strategies to address individual and structural determinants of stigma are reflected in the recommendations that emerged from the UNAIDS-supported study conducted in Mumbai and Bangalore hospitals. Specifically, to reduce stigma and discrimination against PLHA in clinical settings, the authors called for further training of health care workers and greater support by management to ensure that staff practice universal precautions, provide quality care, and are sensitive to human rights principles, such as informed consent and confidentiality (UNAIDS 2001).

In India, the National AIDS Control Organization (NACO) has undertaken steps to ensure quality HIV care and support in medical institutions, including training health care workers to improve case management and HIV counseling and testing practices. However, these measures alone are likely not sufficient to ensure high quality and humane care and support for PLHA in clinical settings.

In response to the need for specific efforts to address stigma and discrimination in hospitals and for empirical evidence to demonstrate program effectiveness in institutional settings, the Horizons Program, SHARAN (an Indian NGO), and the Institute of Economic Growth collaborated with NACO and three New Delhi hospitals to conduct an operations research project. The collaboration aimed to develop and test tools and approaches to guide hospitals and other major medical institutions in upgrading their systems and services to provide timely, appropriate, and humane care for PLHA. A basic premise of the project was that establishing a "PLHA-friendly" environment required tailored interventions to protect the interests and well-being of both patients and staff.

\section{Study Goal and Objectives}

The goal of this operations research was to reduce AIDS-related stigma and discrimination and improve the quality of care for PLHA in the hospital setting. The underlying assumption was that both individual and institutional factors need to be addressed in order to improve care, including the knowledge and attitudes of staff members, hospital policies and procedures, and services and supplies. 


\section{Hgrizons}

The objectives of the research project were to:

- Identify the causes and manifestations of stigma and discrimination against PLHA in hospitals.

- Examine the strengths and limitations of existing services for HIV-infected individuals.

- Use this information to design an intervention package for motivating hospitals to become more PLHA-friendly while simultaneously meeting the safety concerns of health care providers.

- Assess the outcomes of the intervention package on staff knowledge, attitudes, and reported practices, and the implementation of action plans to reduce AIDS-related stigma and discrimination. 


\section{Methods}

\section{Research Setting}

New Delhi was selected as the study site for a number of reasons. First, there were various large and wellaccessed public and private health care institutions recognized for quality services. Second, working in New Delhi provided an opportunity to work in public hospitals administered by both the central government and the state government. This involvement of the central and state public health system offered the potential for greater impact on policy and program design and potential for scale-up.

Third, although the prevalence of HIV infection in New Delhi was estimated to be low when the study began, anecdotal information from AIDS service organizations and health practitioners indicated that almost all large hospitals in the city were providing medical care to patients with HIV or AIDS. In addition, there were reports of widespread stigma, discrimination, and denial of services to PLHA in these health care settings. Moreover, there were regular reports in newspapers about violations of human rights of PLHA by health care institutions and instances of legal action initiated by AIDS service organizations against hospitals for denial of care.

Finally, the researchers believed that efforts undertaken at this point of time in New Delhi would be timely in order to prepare health care facilities for an eventual increase in HIV/AIDS patients.

With regard to hospital selection within New Delhi, the researchers sought hospitals that reported admitting and treating HIV-positive patients and that represented a range of administrative functioning (public and private; central and state government administered). A long selection process ensued wherein almost twenty hospitals representing three different administrative structures - central government, state government, and private-were identified from which six were short-listed. These six were selected because they had an in-patient capacity of over 500, employed more than 1,000 health care workers (which would allow for adequate sampling), and were treating HIV-positive patients. Of these six, three were selected on the basis of their interest and willingness to participate in the study, which would entail the assessment of their services and staff, and the implementation of efforts to provide de-stigmatizing care to PLHA.

In each of the hospitals the researchers purposively selected four departments that were most likely to report treating HIV-positive patients. These four departments were medicine, STD and skin, obstetrics \& gynecology, and surgery. The research project was conducted in the in-patient wards of the four departments.

\section{Description of the study hospitals}

The private hospital selected is one of the premier institutions in the country and is recognized and respected for its medical care. It is a 500-bed hospital and caters to a clientele ranging from low to high socioeconomic status. The former receive free or subsidized care in the hospital while the latter, which constitute the majority of patients, pay high costs for quality services. The hospital has an Infection 


\section{Hgrizons}

Control Committee comprised of staff from the departments of microbiology, infectious diseases, nursing, and hospital administration. The hospital does not have an HIV counseling center.

With a 1,568 bed capacity, the state government hospital is the largest of this type in the city. It is linked to a medical teaching college and two super specialty hospitals. This hospital caters to a large population of people from in and around the city. A sizeable proportion of its patient load are low income and come to the hospital because they do not have to pay for services, aside from a nominal fee to get a patient card/registration number. The hospital has a Waste Management Committee to oversee infection control procedures in the hospital. It also has an HIV testing facility and counseling center that is managed by the state government.

The 1,531-bed central government hospital provides medical care to people from all over the city as well as from neighboring states. It also houses a teaching college for doctors and nurses. The majority of the patients are central government employees and are middle or lower-middle income. The hospital charges a nominal fee for patient registration and levies a subsidized charge for diagnostic tests that would cost double if done in a private institution. The hospital has an Infection Control Committee headed by the head of the medicine department as well as a patient grievance cell headed by the microbiology consultant. In addition, the hospital has a counseling center that provides HIV voluntary counseling and testing.

\section{Study Design}

A pre-test/post-test, cross-sectional design was used to evaluate the impact of the intervention on stigma and discrimination in participating hospitals. The study design allows for an assessment of changes over time in each of the experimental hospitals, before and after the intervention. However, the researchers recognize that the use of a pre/post cross-sectional research design does not allow for assessment of changes in individuals over time.

The study team decided not to employ a control group for the following reasons: (1) the intervention package to be evaluated was entirely new, therefore investing in a control group was felt to be more appropriate after the intervention had been piloted and refined; (2) study hospitals varied so greatly in nature that no single institution could serve as a meaningful control hospital for comparison to the other hospitals; and (3) there was little incentive for an institution to participate as the control group and undergo intensive research procedures without any benefit to itself.

As shown in Figure 1, after site selection the researchers began the study with a period of formative research. The researchers used this information to develop measures and tools for assessing stigma and discrimination on both an individual and an institutional level. This was followed by the intervention research phase, which included a baseline assessment, the design and implementation of the intervention, and an endline assessment to measure the effectiveness of the intervention. 
Figure 1 Study design and timeline

\begin{tabular}{|c|c|c|c|c|c|}
\hline \multicolumn{6}{|c|}{2000 - - } \\
\hline $\begin{array}{c}\text { Site } \\
\text { selection }\end{array}$ & $\begin{array}{l}\text { Formative } \\
\text { research }\end{array}$ & $\begin{array}{l}\text { Development of } \\
\text { indicators and } \\
\text { instruments }\end{array}$ & $\begin{array}{c}\text { Baseline } \\
\text { assessment }\end{array}$ & $\begin{array}{c}\text { Intervention } \\
\text { development and } \\
\text { implementation }\end{array}$ & $\begin{array}{c}\text { Endline } \\
\text { assessment }\end{array}$ \\
\hline
\end{tabular}

\section{Study population and data collection}

In each hospital three levels of health care workers who were most in contact with patients on a daily basis through providing hands-on care were recruited as study participants. These were doctors, nurses, and ward staff. Doctors and nurses provide medical care and ward staff are responsible for the daily cleaning of the wards and departments. Hospital administrators and managers and PLHA and their caregivers also participated in the study.

Table 1 provides information about the data collection methods for each phase of the study. As shown, the formative phase consisted of 59 key informant interviews with hospital staff, clients receiving inpatient care, and caregivers, as well as 30 structured observations (of five hours each for a total of 150 hours of observations) of the hospital environment and of provider-patient interactions.

Following the formative research and design of instruments, a baseline survey was conducted in all sites. Using stratified random sampling, a proportional representation of the three levels of health care workers were selected from the four departments. While the private and public hospitals varied in size, the staffing size was similar in all three hospitals.

The number of nursing and ward staff in each of the hospitals was greater than the number of doctors, therefore to select a proportional representation of the staff the researchers decided that 50 percent of nurses and ward staff and 25 percent of doctors in each of the four departments would be enrolled for the study. To select the specified proportion of study respondents, first a list of eligible staff in each category was drawn up, and then the required number of respondents were randomly selected from this list using log tables. In each hospital, 44 or 45 doctors, 125 nurses, and 125 ward staff were interviewed at baseline. In all, a representative sample of 134 doctors, 375 nurses, and 375 ward staff, totaling 884 health care workers, were interviewed from the three hospitals at baseline.

Data from the baseline survey show that doctors and ward staff were predominantly male whereas all the nursing staff were female. Doctors had the youngest mean age (31.2 years) and ward staff the oldest (37.8 years). Nearly two-thirds (65 percent) of doctors were below 30 years old, compared to 49 percent of the nurses and 33 percent of the ward staff. The majority of all staff interviewed had a service tenure of less than 10 years. While all doctors and nurses had advanced educational qualifications, the educational background of ward staff varied from illiteracy to post graduate degrees. Almost one-fourth of the ward staff had no schooling but reported having basic literacy skills.

A follow-up survey was conducted six to eight months after the intervention activities were completed using the same baseline survey instrument, with additional questions to assess exposure to the intervention activities. The same sampling technique used for the baseline survey was used to recruit a 


\section{Hgrizons}

total cross-sectional sample of 885 health care workers from the three hospitals for the endline assessment. At endline, the characteristics of staff who completed the survey were similar to those at baseline.

Also as part of the endline assessment, 24 key informant interviews were conducted with hospital managers to find out their perceptions of changes among staff and in hospital systems.

Table 1 Data collection matrix

\begin{tabular}{|c|c|c|c|c|}
\hline Phase & Method & $\mathbf{N}$ & Respondents & Topic \\
\hline \multirow[t]{3}{*}{$\begin{array}{l}\text { Formative } \\
\text { Research }\end{array}$} & $\begin{array}{l}\text { Qualitative- } \\
\text { key-informant } \\
\text { interviews }\end{array}$ & 59 & $\begin{array}{l}\text { Hospital managers (3), } \\
\text { doctors (12), nurses (12), } \\
\text { ward staff (6), counselors (2), } \\
\text { HIV-positive patients (12), and } \\
\text { care givers (12) }\end{array}$ & $\begin{array}{l}\text { Practices, attitudes of HCWs, } \\
\text { hospital policies on HIVIAIDS } \\
\text { care management, and patient } \\
\text { experiences }\end{array}$ \\
\hline & $\begin{array}{l}\text { Structured } \\
\text { observations }\end{array}$ & 30 & $\begin{array}{l}\text { Doctors, nurses, and ward } \\
\text { staff }\end{array}$ & $\begin{array}{l}\text { Infection control procedures } \\
\text { used by HCWs }\end{array}$ \\
\hline & $\begin{array}{l}\text { Qualitative } \\
\text { FGD }\end{array}$ & $\begin{array}{c}6 \\
(40)\end{array}$ & $\begin{array}{l}\text { PLHA seeking care in NGO } \\
\text { care centers/hospices }\end{array}$ & $\begin{array}{l}\text { PLHA health seeking behavior } \\
\text { and experiences of S\&D in } \\
\text { hospitals }\end{array}$ \\
\hline $\begin{array}{l}\text { Baseline } \\
\text { assessment }\end{array}$ & $\begin{array}{l}\text { Quantitative- } \\
\text { structured } \\
\text { questionnaire }\end{array}$ & 884 & $\begin{array}{l}\text { Doctors (134), nurses (375), } \\
\text { and ward staff (375) in three } \\
\text { hospitals }\end{array}$ & $\begin{array}{l}\text { Knowledge, attitudes, and } \\
\text { practices regarding care and } \\
\text { management of PLHA }\end{array}$ \\
\hline \multirow[t]{2}{*}{$\begin{array}{l}\text { Endline } \\
\text { assessment }\end{array}$} & $\begin{array}{l}\text { Quantitative- } \\
\text { structured } \\
\text { questionnaire }\end{array}$ & 885 & $\begin{array}{l}\text { Doctors (135), nurses ( } 375) \text {, } \\
\text { and ward staff ( } 375) \text { in three } \\
\text { hospitals }\end{array}$ & $\begin{array}{l}\text { Knowledge, attitudes, and } \\
\text { practices regarding care and } \\
\text { management of PLHA }\end{array}$ \\
\hline & $\begin{array}{l}\text { Qualitative- } \\
\text { key-informant } \\
\text { interviews }\end{array}$ & 24 & $\begin{array}{l}\text { Medical superintendents, } \\
\text { heads of departments, } \\
\text { nursing-in-charge, and } \\
\text { sanitary supervisors }\end{array}$ & $\begin{array}{l}\text { Perceived changes in hospital } \\
\text { systems; staff knowledge, } \\
\text { attitudes, and practices } \\
\text { regarding PLHA care; and } \\
\text { management }\end{array}$ \\
\hline
\end{tabular}

Change in data collection: As per the initial research design HIV-positive patients were to be included as survey respondents to provide insights into manifestations of stigma and discrimination (at baseline) as well as insights about the effectiveness of the intervention (at endline). However, it proved very difficult to identify such patients. Only five were recruited and completed the baseline survey over a period of four months from all three hospitals. Possible explanations for this include: the majority of HIV-positive patients receiving hospital services may have been out-patients instead of in-patients, some PLHA may conceal their status in order to improve their chances of receiving care, and staff may have been reluctant to ask PLHA to participate in the study. Because of the small number of patients recruited at baseline in 
the hospitals, the researchers instead undertook additional qualitative research with PLHA not currently hospitalized who were clients of local AIDS service NGOs. Six focus group discussions involving a total of 40 PLHA and NGO care providers were conducted that explored health needs and health seeking behavior, satisfaction and comfort with services, and reasons for seeking or avoiding hospital services. These findings have been incorporated in the section on formative research findings.

Therefore, as HIV-positive patients were not recruited during baseline, it was decided not to include them in the follow-up survey as well. The study thus focuses on assessing changes in self-reported knowledge, attitudes, and practices of a cross-sectional sample of health care workers following the intervention.

\section{Measures}

To measure changes in stigmatizing and discriminatory attitudes and behaviors among health care workers, appropriate tools are needed. Although tools have been developed to assess stigmatizing beliefs and practices in general, many of them have been developed in the United States. Similarly, examples of tools to measure stigma among health care workers can be found, but in general, these are for Western audiences (van Brakel 2006). Because of this, these tools have not addressed issues that may be particularly relevant in the healthcare setting in the developing world. For example, research conducted by Bharat et al. for UNAIDS (2001) in Indian health care settings found that disclosure of HIV test results to family members of PLHA without consent from the person in question was a fairly common practice. Another relevant issue in the Indian context concerns challenges in implementing Universal Precautions correctly, due to a lack of adequate resources and materials.

The formative research findings identified the important domains of stigmatizing and discriminatory behaviors and attitudes toward PLHA in health care settings. This guided the researchers to develop two measurement tools: (1) The PLHA- friendly Checklist to assess how well the hospitals reach, serve, and treat HIV-positive people as well as provide a safe working environment for staff, and (2) the stigma index to measure stigmatizing and discriminatory attitudes of health care workers.

\section{The PLHA-friendly Checklist}

Formative research findings identified the need for the development of a set of indicators to help measure whether a hospital was free of stigmatizing and discriminatory practices - in other words, "PLHAfriendly.” To aid in the development of the indicators, researchers compiled "gold standards" from national and international guidelines and policies on the human rights of people living with HIV/AIDS, HIV testing and counseling, infection control, and care and management of HIV/AIDS. Also, keeping in mind the findings from the formative research that highlighted the needs and rights of health care workers to work in a safe environment, the indicators were expanded to encompass institutional provision of adequate facilities and supplies for staff. The PLHA-friendly indicators to assess health care workers' practices were categorized under five key domains:
1. Access to care services
2. Testing and counseling
3. Confidentiality
4. Infection control
5. Quality of care 


\section{Hgrizons}

The indicators were compiled into a checklist that was used with hospital managers as a self-assessment tool to identify how well their facility served HIV-positive people and provided a safe working environment for staff. In addition, the tool assisted managers to set goals for the improvement of services for PLHA as well as for their staff.

The checklist was designed in a simple format to be used by managers alone or together with staff, and can be applied to large hospitals, clinics, or specific departments (see Appendix A, page 56). Users of the checklist can use hospital records, survey data, observations, or simply "guesstimates" to rate their own institution.

Within each of the five domains, there are four sub-domains:

1. Practice (Staff practices and behaviors)

2. Training (Building and maintaining the capacity of staff to practice the gold standards)

3. Quality assurance (Institutional mechanisms to monitor and ensure the practice of the gold standards)

4. Policy (Institutional rules and regulations stipulating or enforcing the gold standards)

In each of these sub-domains, there are between one and five Checklist items in the form of a simple statement that represents a gold standard. Managers alone or with staff indicate the extent to which this occurs in their institution: always, sometimes, or never.

These standards were reviewed and endorsed by NACO and by the hospitals participating in the study through a series of consultative discussions.

\section{Stigma index}

The researchers focused on two key constructs that emerged from the formative research-(1) attitudes toward PLHA (e.g., men who get HIV/AIDS get what they deserve) and (2) attitudes toward health carerelated practices (e.g., patients with HIV should be kept at a distance from other patients). The researchers then conducted a review of available national and international literature on stigma reduction interventions and measures to supplement and finalize a list of candidate items (50 items) that matched the identified domains. These items were then reviewed by a team of specialists with experience in HIVrelated stigma in India. After much deliberation and discussion about the wording, relevance, and usefulness of the items, ten items were rejected. This revised list of 40 items was then translated and pretested in the participating study hospitals, with 45 respondents selected from departments other than the four selected for the study. Based on this pre-test, eight other items were removed (due to a lack of clarity, etc.) and a list of 32 items was short-listed for use in the baseline survey. Twenty-two items were worded as statements and 11 were worded as questions.

Following the baseline survey (which included 884 doctors, nurses and ward staff) and a review of the responses to the stigma items, it was determined that some questions were either unclear to respondents, or always solicited the same response, and they were removed from the index list. After a final consultation, 21 items were retained in the index. These items address the main domains that emerged from the formative research and included both stigmatizing and non-stigmatizing statements. Scoring was done on a three-point Likert scale (agree, can't say, disagree), ranging from 1 to 3, with a maximum total 
score of 63 for the 21 items. For scoring, each of the statements was weighted as negative (stigmatizing statements) or positive (non-stigmatizing statement), and scored accordingly. For example, those who responded as 'agree' to a stigmatizing (or negative) statement were scored as 3 and to a non-stigmatizing (or positive) statement as 1 . Similarly, those who disagreed with a positive statement were scored as 3 and to a negative statement as 1 . Those respondents who were unable to agree or disagree with the statements were scored as 2 . Thus, a higher score on the index denotes a higher level of stigma. The internal consistency reliability for this index in the baseline survey was 0.742 (Cronbach's alpha).

\section{Table 1 Stigma index}

\section{Attitudes toward PLHA}

1 People living with HIVIAIDS have a right to decide who should know about it.

2 People with HIVIAIDS should still be allowed to get married, as long as both partners know about it.

3 HIV-positive women should not get pregnant.

4 HIVIAIDS spreads due to immoral behavior.

5 Men who get HIVIAIDS get what they deserve.

6 Sex workers are the only women who have to worry about getting HIVIAIDS.

7 Men who go to sex workers or use drugs are the only men who have to worry about getting HIVIAIDS.

8 A woman who gets HIVIAIDS gets what she deserves.

9 Would you be willing to share a meal with an HIV-positive person?

10 If you knew that a foodseller had HIVIAIDS would you buy food from him?

11 Would you be willing to move into a home if the neighbor was HIV-positive?

12 If you found out that a co-worker has HIVIAIDS would you be willing to work with him/her?

\section{Attitudes toward health care related practices}

13 Patients' blood should never be tested for HIV without their consent.

14 Patients who test positive have the right to decide whether or not their relatives should be informed.

15 When a person tests positive, the doctor should inform the patient's partner.

16 The need for consent is exaggerated. HIV tests should be handled like any other blood test.

17 HIVIAIDS patient should be made to pay for gloves, AIDS kits, and other infection control supplies.

18 All pregnant women should be tested for HIV.

19 Patients with HIVIAIDS should be kept at a distance from other patients.

20 Clothes and linen used by HIV patients should be disposed of or burned.

21 Patients should be tested for HIV before surgery. 


\section{Hgrizons}

\section{Ethical Procedures}

The study investigators strictly adhered to ethical research procedures. All participants underwent informed consent prior to the interviews and were assured that the information would be confidential. Staff, in particular, were assured that their individual responses would not be shared with their superiors or anyone else outside of the research team. After receiving written consent from staff, interviews were conducted in private settings on the hospital premises.

A two-stage recruitment process was used for HIV-positive patients. First, the research team contacted providers who were already aware of their clients' HIV status. The providers were asked to approach patients on behalf of the research team and review the informed consent form that outlined the study purpose and risks and benefits of participating in the research with the patients. If the patient gave his/her consent to participate, then the research team would again seek informed consent from the patient. This was to ensure that they were aware of all the procedures and were willing to participate in the research of their own volition and not under any duress or pressure from the provider. Interviews were conducted in private settings and confidentiality of participants' HIV status and responses was guaranteed.

Completed questionnaires were stored in locked cupboards after removing all personal individual identifiers (these were stored separately). Access to this data was restricted to the research team.

A possible risk for the hospitals participating in the study was negative publicity if research results identified shortcomings in services. As this research was intended not to single out problems, but to support hospitals interested in improving their services for PLHA, the researchers restricted dissemination of the hospital-disaggregated findings only to the participating hospitals to guide the development of their action plans and document hospital accomplishments. Otherwise, the data are presented in aggregate across the three hospitals in this and other reports.

\section{Data Management and Analysis}

Data from all three hospitals were combined and analyzed together to reflect overall changes postintervention rather than reporting on individual hospitals. This was done to address the concerns of NACO, the Delhi State AIDS Control Society, and the participating hospitals about not highlighting any one hospital as a more stigmatizing environment or less patient-friendly than the others.

The formative research data was transcribed from the researchers' field notes. The transcripts were reviewed by the research team and study advisors, who determined key themes for coding and interpretation of study findings. Quantitative data were double-entered by two data entry operators using Epi-Info software. The baseline and endline survey data from all three hospitals were each merged into one data file. Data analysis was conducted with two software packages-SPSS 11.0 for Windows and STATA Intercooled Version 7.0 - to determine the impact of the intervention. Univariate analysis included frequencies and distribution of all study variables and bivariate analyses were conducted with both pre- and post-intervention data. Pearson's Chi square test was used to determine the significance of the differences between pre-test and post-test results. A p-value of less than .05 was used as the threshold for significance. In this report, an asterisk $(*)$ indicates that the results are statistically significant at or below the .05 level. 
Analysis of the stigma index measures included associations between the combined index scores and other key study variables, such as HIV-related knowledge of health care workers and health care workers' practices as listed in the Checklist. In addition, health care workers' pre-test and post-test measures were also compared. Associations between these measures were tested by comparing change in mean scores between the two measures (baseline vs. endline) via t-tests of the means.

Also, for ease of interpretation, the total stigma index scores were trichotomized to categorize three levels of stigmatizing attitudes - low stigma (mean score 21-34), medium stigma (34-48), and high stigma (4963). To determine shift in stigma levels between pre-test and post-test measures, Pearson's Chi square test of independence was used. 


\section{Hgrizons}

\section{Results from the Formative Research and Baseline Survey}

Interviews with health care workers and patients were undertaken to provide both a service provider and a client perspective about stigmatizing and discriminatory attitudes and practices in the hospital setting. Health care workers were asked about the provision of care to HIV-positive patients; patients and their caregivers were asked about their in-patient care experiences. PLHA who were clients of AIDS service organizations were also interviewed about their experiences the last time they accessed hospital services for care and about their health seeking behavior.

\section{Attitudes of Health Care Workers}

PLHA informants reported confronting stigma and discrimination in several forms in both public and private hospitals, including judgmental and condescending attitudes from health care workers. According to one patient, some staff members were inquisitive about how he got infected with the HIV virus and would ask him about it rudely.

They asked me, "how did you get this, what all did you do, where has it come from." I feel that they are concerned how I got the disease.

Interviews with health care workers elicited similar examples of judgmental and prejudiced attitudes; some health care workers blamed people for their infection.

High risk population means lower class people-they live in slums in unhygienic conditions. One sleeps with anybody and everybody; extramarital affairs are common and also drug users and sex workers come in this category.

When asked about hospital service delivery, some PLHA noted that a common initial experience of discrimination of PLHA by hospitals is being denied care, experiencing a delay in treatment, or being referred to other hospitals.

We are often refused treatment in... hospitals. They tell us "we have no bed, we have no empty bed." Another thing that they say is "we don't have facilities for treating HIV." They then refer us to other hospitals.

The doctor refused to examine me for almost two months. Even stopped doing my dressing. He just told me to continue with my medicines. He also referred me to another hospital for an operation that he wouldn't do as it would be very costly for me. 


\section{Denial of Care}

When asked about their own hospitals, almost all staff said that treatment was not refused to anybody seeking care because of their disease/infection status. In fact, doctors in the central government hospital felt that their hospital had become a "dumping" ground for all other health care institutions that did not want to care for PLHA and would thus refer people to their facility. Also, all health care workers interviewed reported having treated or worked near an HIV-infected patient and felt that HIV-positive patients were provided the same medical care provided to other patients in the hospital.

However, some staff alluded to differential practices by health care providers of HIV-infected in-patients. For example, some of the staff from all of the study hospitals reported some type of segregation and isolation of patients because of their HIV status. In one of the hospitals some of the staff reported that HIV-positive patients were placed outside the ward away from other patients or given a corner bed that was placed at a noticeable distance from other beds in the ward.

There is a separate bed which is earmarked for an HIV-positive patient and I see to it that it is not occupied by any other patients.

Also, about half the staff interviewed felt that there should be a separate facility to care for PLHA. To justify this sentiment, some of the respondents mentioned that in a separate AIDS-treatment facility there would be specialized health care workers who would be trained and skilled to provide care to PLHA. This would mean that not only would PLHA get specialized care, they would also be in an environment where health care workers would not be able to discriminate between them and HIV-negative patients.

\section{HIV Counseling and Testing Procedures}

There were mixed responses among staff regarding counseling and testing practices in the three hospitals. Staff from one hospital reported that mandatory testing was carried out, especially for those patients requiring surgery or invasive procedures. In addition, consent of the patient was not taken, nor was the patient provided "professional" counseling as there was no trained HIV/AIDS counselor in the hospital.

Mandatory testing is done routinely with all surgery patients, especially with those patients who arouse a high degree of suspicion.

Some doctors were aware of the procedure of obtaining the patient's informed consent prior to the HIV test. However, they routinely did not ask for informed consent because some of their patients wouldn't understand the consent form owing to their inability to read or write. Staff also noted that because of the fear associated with HIV/AIDS, many people would refuse to be tested if asked for their consent. 


\section{Hgrizons}

I don't think consent matters that much. While it is important in terms of rules, in reality there are people who cannot sign. In that case, consent does not really matter. It is important when the person can understand what consent is. If people know why they are being tested then why get it in writing.

Doctor

I don't take written consent. Whenever I tell a patient to go for HIV testing, Fifty percent of them back out. They are so fearful.

Doctor

Staff of the other two hospitals reported that HIV testing was not mandatory or "routine" prior to surgery in their hospitals. While most doctors reported that they referred their patients to the counseling centers in the hospital for informed consent and counseling, some doctors reported doing so themselves.

Not all patients are tested for HIV, as you may know that before surgery consent needs to be taken.

Only then test can be done, if the patient agrees.

Doctor

Yes we take consent from the patient before the test. We have a form, which we get signed.

Counselor

Counseling is provided. The counseling center does it. Sometimes we also do it.

Doctor

\section{Disclosure of Test Results and Patient Confidentiality}

In all the hospitals, a patient's test results, particularly HIV-positive test results, were often disclosed to the patient's family. This was usually done without the patient's consent. In some cases, the positive test result was not disclosed to the patient at all but only to his/her family members. And, in the case of a negative test result, the patient was usually not informed about the test outcome nor counseled on protecting themselves from future exposure to HIV infection.

If the result is positive, then the doctor tells the patient. The doctor tells the relatives of the patients also.

Nurse

In our hospital only in one gynecology [pregnancy] case, female came out to be positive. We then informed her husband.

Doctor

We don't inform the patient when the result comes out to be negative.

Doctor

Besides improper disclosure of test results, almost all staff reported examples of breaches of a patient's confidentiality. Senior staff argued in favor of "shared confidentiality" wherein the team of treating staff comprising doctors and nurses should know a patient's status. However, in practice ward staff and nontreating staff who did not need to know that a patient was HIV-positive for any clinical reason were also 
often informed of the patient's status. Usually, doctors informed their peers as well as nurses and ward staff in their department about the patient's HIV status so that they could take "adequate precautions" to protect themselves while treating or handling the patient. Similarly, the nurses and ward staff reported informing their peers in the hospital.

HIV status is conveyed to all health care workers.

Doctor

When there is an HIV-positive patient in the ward, doctors tell us to be careful.

Ward staff

Everybody (doctors, nurses, sweepers and ward boys) who works with patients knows the status of the patient.

Nurse

Respondents also reported that in some instances, a patient's HIV status was shared with other patients in the same ward.

The nurse told me that two patients were HIV-positive. She said that the patient in the bed opposite has a dangerous disease-he has HIV.

HIV-negative patient

Confidentiality of a patient's status was also breached by the use of markings or labels on beds, files, and outside the room. "HIV-positive" labels were often written in red ink on the files. The labels on the beds or outside the wards did not proclaim the status so directly; in what was deemed an effort to "conceal" the status of patients from other patients or visitors in the hospital, labels with medical terms were used to "warn” staff to use barrier precautions. Labels commonly reported and observed were " bio-hazard," "high risk," and "barrier precautions." One staff member also mentioned the use of a sign marked "DANGER" posted on top of a patient's bed to signify his HIV-positive status. Sometimes other markers such as separate beds, beds with the number 13 (considered unlucky or inauspicious), or beds placed in a corner of the room at a distance from others were also indicative of patient's HIV-positive status.

Yes, we write HIV-positive with red ink on the case sheet [patient files], so that who ever picks up the case sheet can see the status of the patient.

Nurse

We put bed signs for HIV-positive patients. We write "High Risk Patients."

Nurse

Health care workers' attitudes about confidentiality matched the practices of widespread disclosure of HIV-positive patient's serostatus.

I think everyone should know [of HIV-positive patient's status].

Nurse

At the same time, a few senior staff members felt it was important to maintain confidentiality so as to avoid stigma and discrimination of patients owing to their status. 


\section{Hgrizons}

It is ironic that all know about the status of a patient. They should not know. If a person has a normal amount of knowledge, then he will associate the disease with sex. He looks down upon the patient. In such case, a patient's status should not be revealed.

Doctor

Confidentiality is to be maintained. It is a must till the society becomes such so as to accept HIVpositive patients.

Doctor

Interestingly, while one doctor mentioned a patient's right to information, it was understood as patient's prerogative to ask and then be informed of the test result otherwise if they did not ask, they would not be told. And of course, patients' relatives were informed of the result irrespective of whether they requested the information or not.

Every patient has the right to information. So whosoever asks for the result, we tell him/her. If the patient does not ask, we don't inform on our own. However, relatives are told.

Doctor

Interviews with PLHA patients and caregivers corroborated hospital staff reports of labeling patients as HIV-positive and breaching the confidentiality of a patient's HIV-status.

Bed labels were put up for my baby. All who could read the label knew the status of my baby. Mother of an HIV-positive patient

The doctor did a very wrong thing, he told everyone [of my HIV status]. I am very troubled because of this.

PLHA

The doctors tell the nurses about patients' HIV-infection.

PLHA

To avoid negative repercussions when accessing care, PLHA reported that they utilize a number of strategies, such as concealing their HIV status from medical care providers for as long as possible, or going to a different hospital once their status is known in one.

Actually we [HIV-positive patients] do not disclose our status straight away. What is the use in revealing your status if you will not get treatment? So generally we don't reveal our status in the hospital.

Some PLHA mentioned that they patronize local AIDS service organizations where they are provided nondiscriminatory care, unlike care in hospitals.

In the care home that I was in, the staff would bathe us, give us food, but in... hospitals they don't do anything. In the care home, they spent a lot of money on me and got me treated. 


\section{Use of Universal Precautions by Health Care Workers}

Rather than practicing universal precautions, many hospital staff took inadequate precautions with the general patient population and excessive precautions with patients they thought to be HIV-positive or hepatitis B-positive. This practice seemed to be based on the assumption that if they practice extra precautions with patients known to be suffering from infectious diseases they will be able to safeguard themselves from infection.

We wear gloves with all infectious diseases. While examining HIV patient, we wear double gloves.

Doctor

Sisters wear double gloves for HIV patients.

Nurse

While going near the HIV patient, we wear gloves and we wear masks.

Ward staff

HIV-positive patients perceived the use of excessive barrier precautions by health care workers as differential treatment.

The doctors and nurses wear gloves when they come to me. They keep my sheets separately from the other sheets. While changing my bed sheets, the nurse wears a mask.

PLHA

Interviews with health care workers suggested that precautions were taken not on the basis of the potential risk of a procedure but on the basis of patient's disease status.

No, I don't wear gloves while separating the waste.

Ward staff

You know, every time we cannot wear gloves. Also many times we don't know about it [their status]. We take precautions while dealing with these [HIV-positive] patients.

Nurse

Some doctors were concerned about needle-stick injuries and the potential risk of HIV infection. They stated that since they could not refuse to treat an HIV-positive patient owing to the government's policy, they needed to take adequate precautions such as wearing double gloves, masks, etc.

Even waste management practices varied on the basis of a patient's disease status with extreme steps being reported taken such as burning or disposing of linen and utensils used by HIV-positive patients. Sometimes the patients were asked to bring their own supplies to the hospital, which were then either returned to them or disposed of to avoid using them for other patients.

We burn the linen of the patient. Even utensils of AIDS patients are thrown away. 


\section{Hgrizons}

We tell HIV patients to bring their own thermometer and in case they cannot afford it we provide them with a thermometer. After the patient is discharged, we break the thermometer.

Nurse

\section{Institutional Support for I nfection Control and Universal Precautions}

While none of the hospitals had HIV-specific guidelines at baseline, public hospital managers claimed they followed NACO's prevention and control guidelines related to care and management (which were ratified as national policy in 2002). However, hospital staff were, in general, unaware of these policies and uniform procedures were not followed throughout the hospital. In one of the hospitals, key aspects of the infection control policy were posted outside each department. However, some senior staff were not sure if all staff were following the policy or not.

Although the Infection Control Committees in each of the hospitals had done some work putting together guidelines and undertaking training of staff in their hospitals, these were outdated and sporadic efforts. New knowledge about safeguarding staff was not always shared with all staff members. For example, the staff interviewed had low awareness about post-exposure prophylaxis (PEP) and its potential to reduce the risk of infection following potential exposure to HIV. Also, most of the staff interviewed were not aware if PEP was available in their hospital for their use or how to access it.

I don't know whether PEP is available. As of now there is no policy on it.

Doctor

There is no provision for PEP here but all staff are given vaccination for Hepatitis-B prevention.

Nurse

Some staff, especially ward and other junior staff, reported never having received training in infection control, despite widespread concerns about infection and exposure to medical waste. Almost all nursing and ward staff expressed the need for ongoing training on the transmission and prevention of new diseases and on infection control procedures to be followed not just in the hospital but also in their home settings. However, some doctors felt they did not need in-house training but needed to attend outside symposiums on different infectious diseases.

It will be good if training is given. It should be on new diseases, not just HIV but others as well. Also, tell us about precautions to be taken at work and also at home.

Nurse

\section{Stigmatizing Attitudes and Practices Among Health Care Workers}

Stigmatizing attitudes of health care workers at baseline was assessed using the 21-item stigma index. Individual items were scored using a three-point Likert scale (1, 2, and 3) to provide a total score ranging from a minimum of 21 to a maximum of 63 for the 21 items. The mean score for the entire group of health care workers $(n=884)$ was 42.79 , with individual scores ranging from a minimum of 23 to a maximum of 61 . There was a significant difference between the mean scores of the three groups of health 
care workers ( $\mathrm{p}<.0001)$ : ward staff had the highest mean score $(47.80)$, followed by nurses (39.99), and then doctors (36.60). This indicates that ward staff had the most stigmatizing attitudes toward HIVpositive people.

When stigma scores were trichotomized, nearly two-thirds of all staff (64 percent) fell into the moderate stigma category and 24 percent were in the high stigma category. Only 12 percent were classified in the low category (Figure 2). Stigma scores were similar across the three participating hospitals and therefore only combined scores are presented in the report.

Figure 2 Levels of stigmatizing attitudes of health care workers at baseline

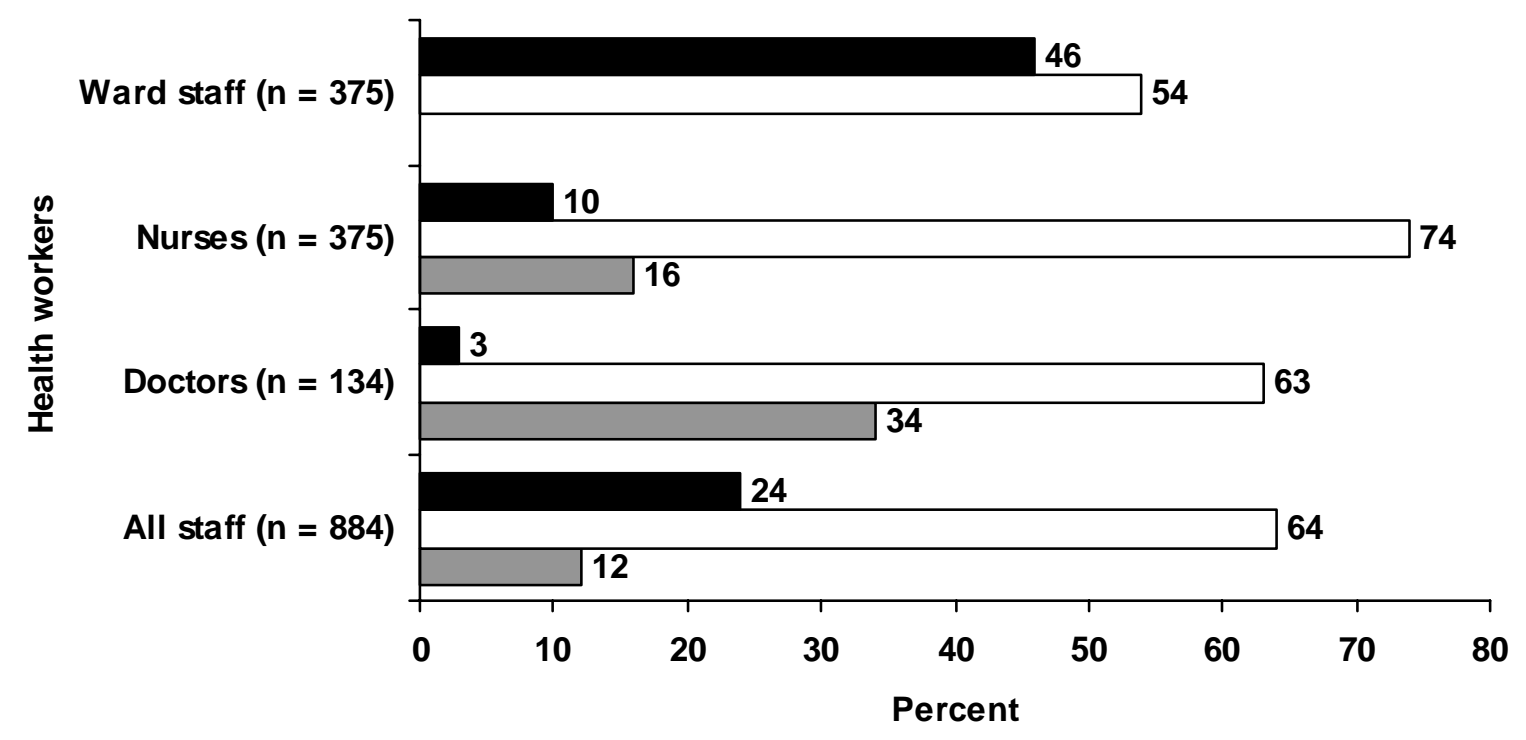

L Low $\square$ Moderate $\quad$ High

\section{Associations between stigma index scores and HIV knowledge and practices}

As part of the baseline survey, staff's knowledge about general HIV transmission and transmission in health care settings was assessed. For each knowledge question, the mean stigma index score for those who answered correctly was compared to the mean score for those who answered incorrectly (Table 2). For example, staff who believed that HIV can be transmitted by casual contact (such as touch, breath, saliva, etc.) had higher stigma scores than those who did not have the same misconceptions. Similarly, health care workers who responded correctly by answering that hepatitis $\mathrm{C}$ was more easily transmitted than HIV from a patient to a health care worker in a hospital setting had a lower mean score on the stigma index compared to those who believed HIV was more easily transmitted. 


\section{Hgrizons}

Table 2 Association between health care workers' HIV transmission knowledge and mean stigma index scores at baseline

\begin{tabular}{|c|c|c|c|}
\hline & \multicolumn{2}{|c|}{$\begin{array}{c}\text { Mean stigma index scores } \\
\text { (higher score = greater } \\
\text { stigma) }\end{array}$} & \multirow[t]{2}{*}{ Significance $^{\star}$} \\
\hline & $\begin{array}{l}\text { Yes } \\
\text { (Incorrect } \\
\text { response) }\end{array}$ & $\begin{array}{l}\text { No } \\
\text { (Correct } \\
\text { response) }\end{array}$ & \\
\hline \multicolumn{4}{|l|}{ 1. HIV can be transmitted by } \\
\hline Touching PLHA & 50.28 & 42.20 & * \\
\hline Breath of PLHA & 48.48 & 41.79 & * \\
\hline Saliva/sputum of PLHA & 44.14 & 41.54 & * \\
\hline Mosquito bite & 45.94 & 40.93 & * \\
\hline \multicolumn{4}{|l|}{ 2. In hospital setting, HIV can be transmitted by } \\
\hline Handling dry linen without gloves & 47.76 & 41.73 & * \\
\hline Blood splash on intact skin & 47.36 & 40.93 & * \\
\hline Serving food to HIV-positive patient & 45.83 & 42.63 & NS \\
\hline Coming close to HIV-positive patient & 49.77 & 42.25 & * \\
\hline $\begin{array}{l}\text { HIV has a greater risk of transmission from a } \\
\text { patient to health care worker than hepatitis } C\end{array}$ & 45.61 & 40.31 & * \\
\hline
\end{tabular}

${ }^{*} \mathrm{p}<.05$; t-test

NS = not significant

Associations between stigma index scores and reported stigmatizing or discriminatory practices by health care workers were also examined. Some questions relating to general hospital-wide practices were asked of all staff, while other questions that were relevant to only certain cadres of health care workers were asked of that particular subgroup. For example, only doctors were asked about their experiences providing HIV counseling and testing services, whereas all health care workers were asked about whether they intentionally avoided touching HIV-positive patients. Also, only a sub-sample of ward staff who delivered food to in-patients were asked about glove use for undertaking this task for HIV-positive patients.

Staff who scored higher on the stigma index were more likely to report stigmatizing or discriminatory practices, such as avoiding going near HIV-positive patients, sharing the patient's HIV status with nontreating staff or family members, or inappropriately using gloves during casual contact with HIV-positive patients (Table 3). 
Table 3 Association between health care workers' discriminatory practices and mean stigma index scores at baseline

\begin{tabular}{|c|c|c|c|}
\hline & \multicolumn{2}{|c|}{$\begin{array}{c}\text { Mean stigma } \\
\text { index scores } \\
\text { (higher score }= \\
\text { greater stigma) }\end{array}$} & \multirow[t]{2}{*}{ Significance* } \\
\hline & Yes & No & \\
\hline \multicolumn{4}{|l|}{ Reported practices of all health care workers $(n=884)$} \\
\hline \multicolumn{4}{|l|}{$\begin{array}{l}\text { To protect themselves from HIV infection while working in the } \\
\text { hospital, staff ... }\end{array}$} \\
\hline ... avoid going near HIV-positive patients & 45.40 & 42.53 & * \\
\hline ... avoid touching HIV-positive patients & 46.18 & 42.46 & * \\
\hline \multicolumn{4}{|l|}{ Reported practices of doctors and nurses $(n=509)$} \\
\hline Share HIV-positive status of patients with ward staff & 39.73 & 35.43 & * \\
\hline \multicolumn{4}{|l|}{ Reported practices of doctors } \\
\hline $\begin{array}{l}\text { Of those doctors who received an HIV-positive test result } \\
\text { for a patient }(n=48) \text {, informed family members }\end{array}$ & 36.14 & 34.90 & NS \\
\hline $\begin{array}{l}\text { Of those doctors who informed family members }(n=28) \text {, did } \\
\text { not obtain patient's consent prior to informing family }\end{array}$ & 36.94 & 35.08 & NS \\
\hline $\begin{array}{l}\text { Wear gloves for external exam of HIV-positive patients } \\
(n=133)\end{array}$ & 37.17 & 35.08 & * \\
\hline \multicolumn{4}{|l|}{ Reported practices of nurses } \\
\hline $\begin{array}{l}\text { Wear gloves to give medicines to HIV-positive patients } \\
(n=364)\end{array}$ & 41.67 & 34.90 & * \\
\hline Always inform relatives about patients' HIV status $(n=336)$ & 41.29 & 39.51 & * \\
\hline \multicolumn{4}{|l|}{ Reported practices of ward staff } \\
\hline $\begin{array}{l}\text { Only wear gloves to transport HIV-positive patients } \\
\text { (not HIV-negative patients) }(n=209)\end{array}$ & 49.09 & 46.09 & * \\
\hline $\begin{array}{l}\text { Only wear gloves for delivering food to HIV-positive } \\
\text { patients (not HIV-negative patients) }(n=46)\end{array}$ & 47.20 & 42.60 & * \\
\hline
\end{tabular}

These findings indicate that respondents with higher stigma scores were more likely to carry out stigmatizing or discriminatory behaviors, such as avoiding casual contact with HIV-positive patients or sharing the HIV status of a patient with staff that do not treat or directly interact with the patient. 


\section{Hgrizons}

\section{Development of the Intervention}

After having received an expression of interest to participate in the operations research project, the study team sought endorsement from NACO and the Delhi State Government to undertake the study in the public sector hospitals, and from the private hospital's chairperson and board members to implement the study in their hospital. Once these approvals were given, the study team consulted with management in each of the study hospitals to appoint a team of nodal hospital staff as key contact persons for coordinating the implementation of the study. A Project Implementation Review Committee (PIRC) was formed to review the research methodology and to design the intervention package. NACO's additional project director chaired the committee.

Findings from the formative research and baseline survey highlighted that the study hospitals needed to address stigmatizing attitudes and discriminatory practices of all levels of health care workers. At the same time, to ensure a hospital environment that would facilitate and support staff attitudinal and behavioral change, hospital systems required strengthening. Thus, the aim of the pilot intervention was to guide and support hospitals in becoming more patient-friendly by building directly upon NACO's existing training, policies, and infection control efforts. The project team defined a patient-friendly hospital as one in which PLHA receive appropriate care (i.e. humane, thorough, timely, clinically appropriate, and respectful); where there is an absence of stigma and discrimination against PLHA; and where staff are confident, competent, and assured of a safe working environment in order to care for patients of unknown or HIV-positive status. A premise of this research was that key policies, training, and services must be in place in order for a hospital to become patient-friendly.

\section{Intervention Components}

The research team engaged the hospital managers in a participatory process to develop action plans to address stigma and discrimination in their hospitals. This participatory process entailed analysis of the baseline data in relation to the PLHA-friendly Checklist by managers and staff in order to reflect on their hospital's achievements in comparison to the gold standards embodied in the Checklist (see page 13 for a description of the Checklist).

Following a results dissemination meeting in each of the hospitals, the hospital administrators put together an intervention team comprised of the nodal staff members as well as heads of department (HOD) of the four departments and the nursing and sanitary supervisors in order to design an action plan for their hospital in collaboration with the research team. As a result of a series of meetings during a three- to six-month period, each of the hospital intervention teams developed an action plan to improve both services for PLHA and working conditions for staff. While the action plans varied by hospital, they all broadly included the same key components as follows: 


\section{Hospital guidelines for HIV/AIDS care and management}

Using the gold standards embodied in the checklist, the team developed a set of norms, or codes of conduct, to guide health care workers in caring for patients in their hospitals, particularly patients infected with HIV. Examples of these policy guidelines include:

- PLHA should have full and equal access to services provided in a non-discriminatory and nonstigmatizing manner.

- HIV testing should be voluntary, informed, specifically consented to, and accompanied by pre- and post-test counseling.

- Information about patients' HIV status should be kept confidential.

- Infection control measures including universal precautions, waste management, and post-exposure prophylaxis should be practiced at all times to ensure safety of both staff and patients.

- Orientation and ongoing training on HIV/AIDS-related issues should be provided to all levels of staff.

- Hospital guidelines should be disseminated to all staff in the hospital.

The policy guidelines were grouped according to five key domains: access to care for PLHA, counseling and testing, confidentiality, infection control, and training and dissemination.

These comprehensive, simply-worded hospital policy guidelines were produced as an English-language booklet and disseminated to all doctors and nurses. Besides the guidelines, this booklet also included references to NACO policy and WHO guidelines as well as a section on operational definitions and explanations of the various policy statements. For ward staff, the guidelines were translated into Hindi and printed as a foldable pamphlet without the details of NACO and WHO policy and operational definitions.

To disseminate the hospital guidelines, Sharan contracted the services of SAHARA, an AIDS service NGO that is well known for its care and support services for PLHA. Staff from SAHARA held several meetings in each of the hospitals with the different levels of health care workers (doctors, nurses, and ward staff) in the four study departments to inform them of the guidelines. Some of these meetings were held impromptu in nursing stations or in the ward staff canteen, involving from 8 to 15 participants. Following discussion and question and answer sessions, the NGO staff distributed the hospital guidelines to all health care workers in the departments. In one of the hospitals, the management organized a halfday seminar with a panel of speakers representing NGOs, government agencies and PLHA groups to debate the key aspects of the guidelines prior to disseminating them to all staff.

\section{Sensitization of health care workers through participatory training led by HIV/AIDS NGOs}

Building on existing HIV/AIDS knowledge and skills-based training in the hospital, an interactive training module was developed to sensitize health care workers about various issues related to HIV/AIDS. This training was intended to complement existing clinical management and infection control training in each of the hospitals. The objectives of the module were to improve staff member's understanding of HIV/AIDS transmission and procedures for infection control and to introduce concepts of confidentiality, patient rights, VCT, and social care and support. This training was aimed at sensitizing health care workers to the needs and rights of PLHA, to improve their negative attitudes, and to clear up 


\section{Hgrizons}

misconceptions and fears in order to ensure the provision of humane and equitable care and treatment. The feasibility and effectiveness of implementing an innovative participatory training module among a group of health care workers was also assessed.

The interactive training module was developed using existing training modules and input from local HIV/AIDS organizations and from PLHA. The module contains eight chapters, each of which includes information and examples of participatory exercises and games to use with participants. The eight chapters are (1) group building, (2) basics of HIV transmission and infection control, (3) HIV testing and counseling, (4) confidentiality and legal issues, (5) stigma and discrimination and ethical issues, (6) continuum of care, (7) site visits to care home, and (8) evaluation and feedback.

The sensitization training was facilitated by representatives of AIDS service organizations and included PLHA. As per their expertise and skills, two or three facilitators were assigned to facilitate each module. For example, a team comprising a lawyer, a person living with HIV, and a human rights activist led the session on ethical and legal issues. In each hospital about 30-40 health care workers were trained in separate groups of doctors, nurses, and ward staff. The training was conducted over a period of two weeks during which two-hour sessions were organized every alternate day as per the staff's convenience. The facilitators used participatory training methods, such as discussions, group exercises, quizzes, games, role plays, and field visits to conduct the training sessions. After each module, the facilitators and participants provided feedback on the structure, content, and methods used during the session.

\section{Expansion and strengthening of HIV testing and counseling services}

The two hospitals that had counseling centers expressed the need for a refresher training program for counselors to strengthen their skills and update their knowledge on HIV/AIDS. The third hospital that did not have a counseling center designated one of their hospital staff as a full-time "counselor" for HIV/AIDS, who was given extensive training on HIV/AIDS counseling techniques and procedures. The study team enlisted the help of one of the lead AIDS service NGOs in the city-identified by the government as the lead HIV/AIDS counseling training agency-to facilitate a rigorous one-week training for the hospital counselors. Following this training, some of the counselors also underwent a shorter refresher training course.

In addition, in the hospital where the counseling center was managed by a team of NGOs, the study team facilitated discussions between the NGOs and hospital management to streamline the counseling and testing procedures.

\section{Educational material on infection control}

Posters containing key messages on infection control, including universal precautions, waste management at ward level, and post-exposure prophylaxis, were developed by an information, education, and communications (IEC) consultant in collaboration with the hospital nodal team in each hospital. Once the key messages and supporting visuals were drafted they were "field-tested" in each of the hospitals with a small group of staff. Based on the feedback from the staff as well as members of the Infection Control 
Committee, the posters were revised and submitted for approval to the hospital management. Once the posters were approved and finalized, they were printed and disseminated in each of the hospitals In each ward, staff were engaged in review and discussion of poster messages; SAHARA staff conducted at least three group discussions in each of the departments with the different levels of health care workers. Following the discussions, the team from SAHARA also engaged hospital staff in posting the IEC materials at key vantage points in each of the hospitals for maximum visibility. 


\section{Hgrizons}

\section{Results from the Assessment of the Intervention}

Both quantitative and qualitative methods were used to assess the differences between baseline and endline measures of respondents' AIDS-related knowledge, attitudes, practices, and perceptions of hospital practices related to the care of PLHA. At endline, qualitative interviews were conducted with hospital managers, administrators, and section heads to gain their insights on the process and impact of the intervention on the hospital environment. Overall, at endline, health care workers expressed greater respect for the rights of patients, including PLHA, and increased their HIV-related knowledge and improved their HIV testing and infection control practices.

This section of the report first presents changes in stigmatizing attitudes as measured by the stigma index, followed by changes in staff knowledge and staff practices from other survey questions. Finally, qualitative findings from interviews with hospital managers about the intervention process and its impact are discussed.

The impact of the intervention on the attitudes of health care workers (HCWs) as measured by the 21item stigma index administered at baseline and endline is presented in three different ways: 1) the change in individual stigma index items, 2) the change in mean stigma index scores, and 3) the change across three different levels of stigma-low, moderate, and high.

\section{Changes in Attitudes toward PLHA}

Of the 12 index items on attitudes toward PLHA, five items assessed support for judgmental views, four items assessed attitudes about personal contact with PLHA, and three items assessed attitudes toward PLHA rights. As shown in Table 4, at baseline, more than two-thirds (68 percent) felt that HIV spreads due to immoral behavior, and nearly half associated HIV/AIDS with marginalized groups such as sex workers (43 percent) and drug users (44 percent). Eighty-one percent favored curtailing PLHA rights to reproduction and 58 percent to marriage. Many would avoid personal contact with PLHA. For example, only 41 percent reported they would share a meal with an HIV-positive person.

At endline, HCWs attitudes improved on 9 of the 12 items; on two items there was a mixed response and one worsened significantly (Table 4). Thus, overall there was a significant reduction in HCWs' judgmental attitudes, improvement in their respect for PLHA rights, and a reduction in fear of casual contact with PLHA. For example, at endline, significantly fewer HCWs agreed that HIV/AIDS spreads due to immoral behavior (68 percent vs. 49 percent), fewer HCWs associated HIV with marginalized groups such as drug users (44 percent vs. 11 percent) and sex workers (43 percent vs. 12 percent), more were in favor of supporting the right to marriage for PLHA (39 percent vs. 46 percent), and more reported they would be willing to share a meal with a person living with HIV (41 percent vs. 71 percent).

The items for which there were either mixed results or HCWs' attitudes did not improve related to blaming PLHA for the disease and restricting their other rights. For example, when HCWs were asked their opinion about the statement, "men who get HIV/AIDS get what they deserve," there was no change in those who agreed over time (37 percent at both baseline and endline), but there was a positive change in those who disagreed with the statement (58 percent at baseline vs. 63 percent at endline). When asked 
whether women who became infected got what they deserved, more HCWs agreed with the stigmatizing statement at endline (32 percent vs. 29 percent at baseline), and the same proportion disagreed (69 percent at both baseline and endline). For both of these items, there was a significant improvement in the attitudes of nurses, but the doctors' attitudes worsened over time. More doctors increasingly blamed men (13 percent vs. 19 percent) and women (5 percent vs. 13 percent) for contracting HIV infection. The item that worsened significantly was HIV-positive women's right to reproduction. Compared to baseline, more HCWs agreed with the statement, "HIV-positive women should not get pregnant" (81 percent vs. 89 percent). Although doctors were less likely to support this statement at endline (71 percent vs. 58 percent), the attitudes of nurses (89 percent vs. 96 percent) and ward staff (75 percent vs. 93 percent) worsened significantly.

Table 4 Changes in attitudes toward PLHA (\% agree)

\begin{tabular}{|c|c|c|c|c|c|c|c|c|}
\hline & \multicolumn{2}{|c|}{ Doctors } & \multicolumn{2}{|c|}{ Nurses } & \multicolumn{2}{|c|}{ Ward staff } & \multicolumn{2}{|c|}{ All staff } \\
\hline & $\begin{array}{c}\text { BL } \\
n=134 \\
(\%)\end{array}$ & $\begin{array}{c}E L \\
n=135 \\
(\%)\end{array}$ & $\begin{array}{c}\text { BL } \\
n=375 \\
(\%)\end{array}$ & $\begin{array}{c}E L \\
n=375 \\
(\%)\end{array}$ & $\begin{array}{c}\mathrm{BL} \\
\mathrm{n}=375 \\
(\%)\end{array}$ & $\begin{array}{c}\text { EL } \\
n=375 \\
(\%)\end{array}$ & $\begin{array}{c}\text { BL } \\
n=884 \\
(\%)\end{array}$ & $\begin{array}{c}E L \\
n=885 \\
(\%)\end{array}$ \\
\hline HIVIAIDS spreads due to immoral behavior & 61 & $56^{*}$ & 57 & $30 *$ & 81 & $66^{*}$ & 68 & $49^{*}$ \\
\hline $\begin{array}{l}\text { Men who get HIVIAIDS get what they } \\
\text { deserve }\end{array}$ & 13 & 19 & 26 & 22 & 58 & 58 & 37 & 37 \\
\hline $\begin{array}{l}\text { Men who go to sex workers or use drugs are } \\
\text { the only ones who need to worry about } \\
\text { getting HIV }\end{array}$ & 10 & 9 & 26 & $8^{*}$ & 74 & $16^{*}$ & 44 & $11^{*}$ \\
\hline $\begin{array}{l}\text { Sex workers are the only women who have } \\
\text { to worry about getting HIV }\end{array}$ & 7 & 9 & 23 & $7^{*}$ & 76 & $17^{*}$ & 43 & $12^{*}$ \\
\hline $\begin{array}{l}\text { A woman who gets HIV gets what she } \\
\text { deserves }\end{array}$ & 5 & $13^{*}$ & 19 & 17 & 48 & $53^{*}$ & 29 & 32 \\
\hline $\begin{array}{l}\text { People living with HIVIAIDS have the right to } \\
\text { decide who should know their status }\end{array}$ & 72 & 84 & 88 & 92 & 69 & 66 & 78 & 80 \\
\hline $\begin{array}{l}\text { People living with HIVIAIDS should be } \\
\text { allowed to get married }\end{array}$ & 79 & 90 & 44 & 50 & 21 & $26^{*}$ & 39 & $46^{*}$ \\
\hline HIV-positive women should not get pregnant & 71 & $58^{*}$ & 89 & $96^{*}$ & 75 & $93^{*}$ & 81 & $89 *$ \\
\hline $\begin{array}{l}\text { Would you be willing to share a meal with an } \\
\text { HIV-positive person? }\end{array}$ & 65 & 76 & 51 & $71^{*}$ & 23 & $71^{*}$ & 41 & $71^{*}$ \\
\hline $\begin{array}{l}\text { If you knew a foodseller had HIV, would you } \\
\text { buy food from him? }\end{array}$ & 75 & 83 & 67 & $90^{*}$ & 30 & $87^{*}$ & 53 & $88^{*}$ \\
\hline $\begin{array}{l}\text { Would you be willing to move into a home if } \\
\text { the neighbor was HIV-positive? }\end{array}$ & 91 & 93 & 81 & $95^{\star}$ & 57 & $92^{*}$ & 72 & $94^{*}$ \\
\hline $\begin{array}{l}\text { If you found out that a co-worker has } \\
\text { HIVIAIDS would you be willing to work with } \\
\text { him/her? }\end{array}$ & 94 & 93 & 94 & $100 *$ & 88 & $97^{*}$ & 88 & $97^{\star}$ \\
\hline
\end{tabular}

$\mathrm{BL}=$ baseline

$\mathrm{EL}=$ endline

${ }^{*} p$ value $<.05$ 


\section{Hgrizons}

\section{Changes in Attitudes toward Discriminatory Hospital Practices}

As per national and international guidelines, obtaining informed consent prior to HIV testing and counseling, protecting confidentiality of patients' HIV status, and practicing universal precautions form the cornerstone of HIV/AIDS care and management in health care institutions. Mandatory HIV testing is a violation of patients' rights, thus voluntary counseling and testing is promoted as the appropriate practice.

Nine stigma index items examined attitudes toward HCWs' practices while caring for HIV-positive patients. These nine items emerged from the formative research findings and clustered around HIV testing (two items), informed consent (two items), disclosure of HIV status (two items), and use of universal precautions (three items).

As shown in Table 5, a large proportion of HCWs at baseline endorsed discriminatory practices. For example, 86 percent supported mandatory HIV testing prior to surgery, half stated that the need for consent is exaggerated, a little less than half disagreed that the patient has the right to decide about disclosing his/her HIV test results to relatives, and a majority felt that HIV-positive patients should be distanced from other patients in the ward and endorsed unnecessary infection control measures.

Post-intervention, there was a significant improvement in five of the nine items. More HCWs supported the need for informed consent prior to HIV testing (41 percent vs. 65 percent) and a patient's right to disclose their HIV status to relatives (57 percent vs. 64 percent). Fewer agreed that the need for informed consent is exaggerated (50 percent vs. 32 percent), that patients with HIV should be kept at a distance from other patients (55 percent vs. 44 percent), and that clothes and linen of HIV-positive patients should be disposed or burned (67 percent vs. 54 percent).

However, there was an increase in support for HIV testing prior to surgery (86 percent vs. 95 percent) and for all pregnant women (79 percent vs. 93 percent). Although the statement about testing all pregnant women for HIV may appear to be beneficial in light of the availability of Nevirapine to reduce the risk of vertical transmission, given HCWs' views about informed consent, this item was interpreted as being discriminatory and in support of mandatory testing.

Almost all health care workers continued to support the negative practice of doctors disclosing patients' status to their partner. As per national guidelines, a health provider can disclose the client's status to his/her partner only when the patient refuses to do so after counseling and the patient has been duly informed that the provider will be contacting the partner. 
Table 5 Changes in attitudes toward health care practices

\begin{tabular}{|c|c|c|c|c|c|c|c|c|}
\hline & \multicolumn{2}{|c|}{ Doctors } & \multicolumn{2}{|c|}{ Nurses } & \multicolumn{2}{|c|}{ Ward staff } & \multicolumn{2}{|c|}{ All staff } \\
\hline & $\begin{array}{c}\mathrm{BL} \\
\mathrm{n}=134 \\
(\%)\end{array}$ & $\begin{array}{c}E L \\
n=135 \\
(\%)\end{array}$ & $\begin{array}{c}\mathrm{BL} \\
\mathrm{n}=375 \\
(\%)\end{array}$ & $\begin{array}{c}E L \\
n=375 \\
(\%)\end{array}$ & $\begin{array}{c}\mathrm{BL} \\
\mathrm{n}=375 \\
(\%)\end{array}$ & $\begin{array}{c}E L \\
n=375 \\
(\%)\end{array}$ & $\begin{array}{c}\mathrm{BL} \\
\mathrm{n}=884 \\
(\%)\end{array}$ & $\begin{array}{c}E L \\
n=885 \\
(\%)\end{array}$ \\
\hline $\begin{array}{l}\text { Patients should be tested for HIV } \\
\text { before surgery }\end{array}$ & 79 & 79 & 92 & $98^{*}$ & 82 & $98^{\star}$ & 86 & $95^{\star}$ \\
\hline $\begin{array}{l}\text { All pregnant women should be } \\
\text { tested for HIV }\end{array}$ & 66 & 69 & 92 & $97^{*}$ & 70 & $97^{*}$ & 79 & $93^{*}$ \\
\hline $\begin{array}{l}\text { The need for consent is } \\
\text { exaggerated; HIV tests should be } \\
\text { handled like any other blood test }\end{array}$ & 60 & $46^{*}$ & 34 & $26^{*}$ & 63 & $32^{*}$ & 50 & $32^{*}$ \\
\hline $\begin{array}{l}\text { Patients' blood should never be } \\
\text { tested for HIV without their } \\
\text { consent }\end{array}$ & 39 & $67^{*}$ & 42 & $66^{*}$ & 40 & $62^{*}$ & 41 & $65^{\star}$ \\
\hline $\begin{array}{l}\text { Patients who test positive have the } \\
\text { right to decide whether their } \\
\text { relatives should be informed }\end{array}$ & 64 & $78^{*}$ & 62 & 63 & 50 & $59^{*}$ & 57 & $64^{*}$ \\
\hline $\begin{array}{l}\text { When a person tests positive, the } \\
\text { doctor should inform the patient's } \\
\text { partner }\end{array}$ & 87 & $75^{\star}$ & 98 & 99 & 93 & $99^{*}$ & 94 & 95 \\
\hline $\begin{array}{l}\text { Patients with HIV should be kept at } \\
\text { a distance from other patients }\end{array}$ & 26 & 21 & 44 & $29^{*}$ & 77 & $66^{\star}$ & 55 & $44^{*}$ \\
\hline $\begin{array}{l}\text { Clothes and linen used by HIV- } \\
\text { positive patients should be } \\
\text { disposed or burned }\end{array}$ & 54 & 56 & 67 & $40^{*}$ & 72 & $67^{*}$ & 67 & $54^{*}$ \\
\hline $\begin{array}{l}\text { HIV-positive patients should be } \\
\text { made to pay for health care } \\
\text { workers' use of additional infection } \\
\text { control supplies }\end{array}$ & 14 & 23 & 12 & 13 & 7 & $12^{*}$ & 10 & $14^{*}$ \\
\hline
\end{tabular}

$\mathrm{BL}=$ baseline

$\mathrm{EL}=$ endline

${ }^{*} \mathrm{p}<.05$

Even though the proportion of respondents who agreed that HIV-positive patients should pay for their own supplies increased at endline (10 percent vs. 14 percent), it is doubtful that hospital workers would endorse this for patients.

\section{Change in Mean Stigma Scores of Health Care Workers}

As shown in Figure 3, the mean score on the stigma index for all health care workers declined significantly at endline (42.79 vs. 38.07; $\mathrm{p}<.05$ ), indicating an improvement in their attitudes toward PLHA and hospital practices. Although ward staff had the highest mean scores at baseline and endline (47.80 and 41.33; $\mathrm{p}<.0001$ ), this cadre of health care workers also registered the largest decrease in mean scores post-intervention. 


\section{Hgrizons}

Figure 3 Changes in mean stigma scores of health care workers

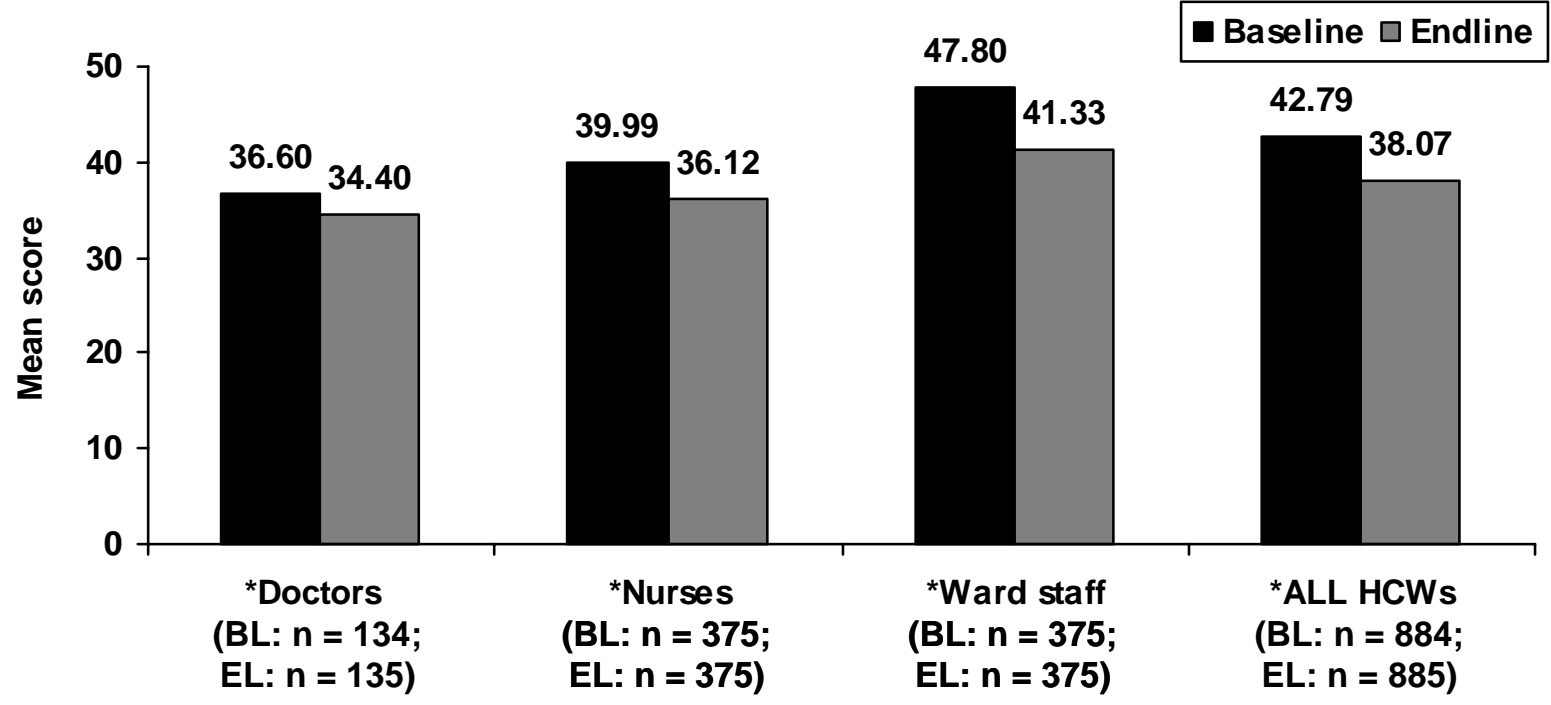

${ }^{*} \mathrm{p}<.05 ;$ t-test

Changes in Stigma Levels of Health Care Workers

As mentioned previously, scores on the stigma index were trichotomized into low (21-34), moderate (3548), and high stigma (49-63). At baseline, only one-tenth of HCWs fell into the low stigma category, two-thirds were in the moderate stigma group, and one-fourth were in the high stigma category (Figure 4a). After the intervention, the proportion of HCWs who were categorized as being the least stigmatizing more than doubled (12 percent vs. 27 percent) and the proportion of respondents in the most stigmatizing category declined considerably (24 percent vs. 7 percent). At both points in time, the majority of HCWs fell in the moderate stigma range, thus indicating that work is still needed to address HCWs' attitudes, particularly relating to fear of contagion in the health care setting.

Disaggregated data clearly indicate that a large proportion of doctors (Figure 4b) and nurses (Figure 4c) improved their attitudes significantly by moving into the low stigma category from the moderate stigma category. There was also a considerable shift among ward staff; a large proportion of them moved out of the high stigma category into the moderate stigma category (Figure 4d). 
Figure 4a Changes in stigma levels by all health care workers

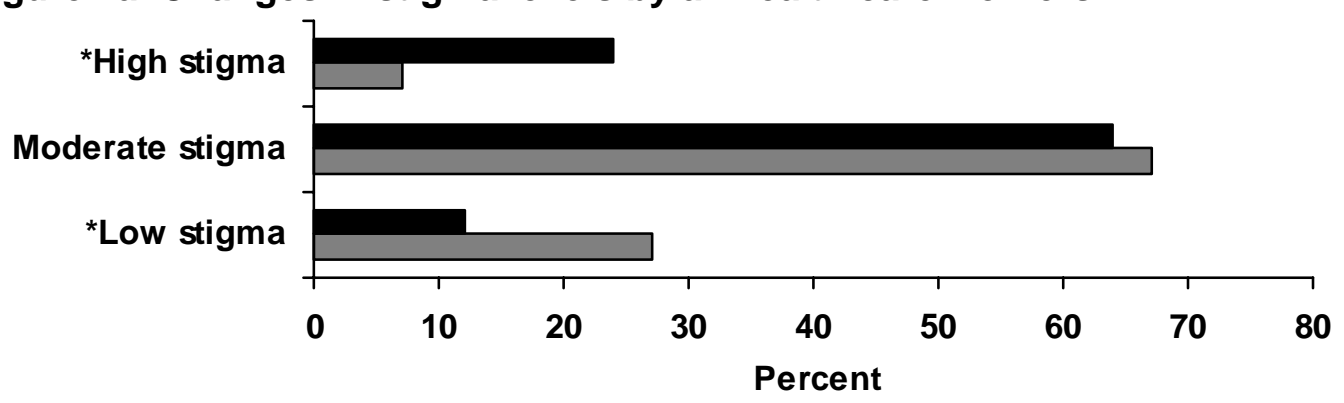

Baseline

$\square$ Endline

Figure 4b Changes in stigma levels by doctors

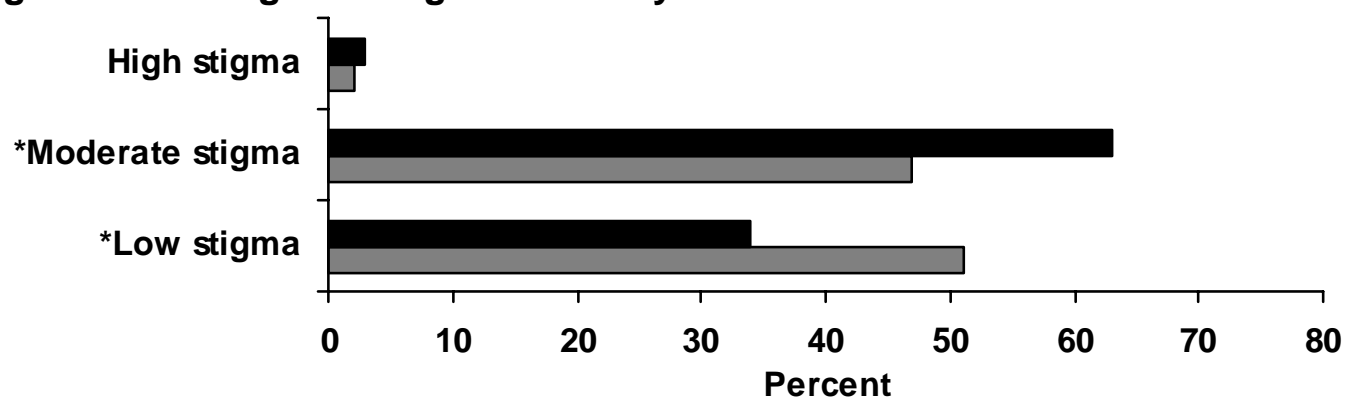

Baseline

$\square$ Endline

Figure 4c Changes in stigma levels by nurses

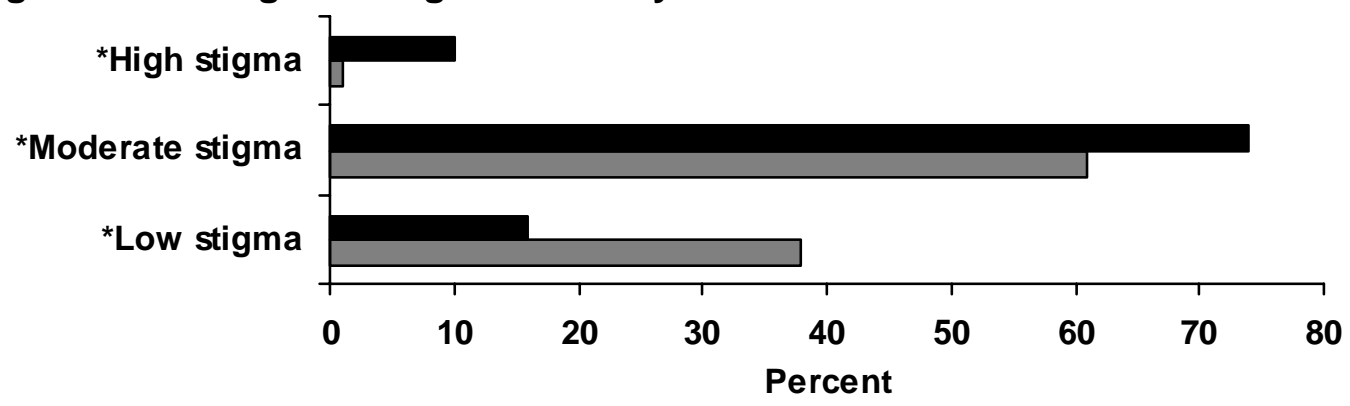

Figure 4d Changes in stigma levels by ward staff

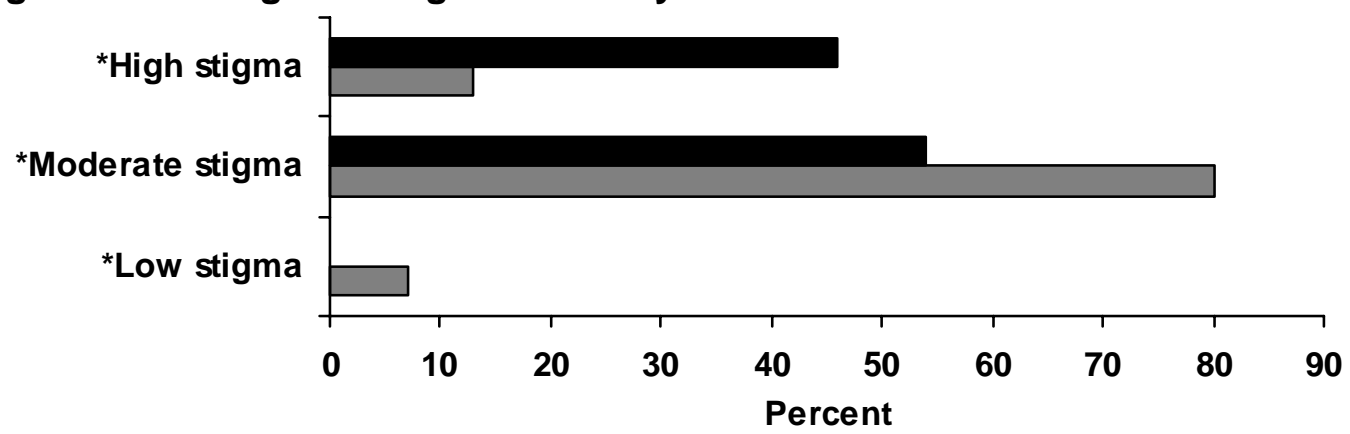

Baseline

$\square$ Endline

${ }^{*} p<.05$ 


\section{Hgrizons}

\section{Changes in Knowledge of HIV Transmission}

At baseline, general knowledge about HIV transmission and prevention and specific HIV knowledge related to working in a hospital was inconsistent among all levels of staff. In addition, knowledge varied dramatically between the different categories of staff. Overall, doctors and nurses had far greater knowledge than ward staff.

At baseline almost all doctors, nurses, and ward staff responded correctly when asked if HIV can be transmitted through unprotected sex, needle sharing, a blood transfusion with untested blood, or from an HIV-positive mother to her child (Table 6). However, a significant proportion of HCWs also appeared to harbor misconceptions about HIV transmission. More than half of ward staff and one-third of doctors and nurses believed that HIV could be transmitted through saliva. Mosquitoes were also perceived to transmit HIV by nearly one-fourth of doctors and nurses and two-thirds of ward staff. Knowledge about modes of HIV transmission in the hospital setting was high among doctors and nurses, but results were mixed for ward staff.

Major improvements in understanding HIV transmission and sound prevention precautions were observed after the intervention, especially among ward staff. For example, there were significant increases in the proportion of ward staff who stated correctly that HIV/AIDS cannot be transmitted by touching a person with HIV/AIDS (80 percent vs. 96 percent), from the breath of a person with HIV/AIDS (64 percent vs. 76 percent), from sharing utensils (67 percent vs. 83 percent), and from sharing clothes (63 percent vs. 86 percent). These changes were corroborated by hospital managers interviewed at endline:

There has been a big change. Earlier ward staff were not willing to touch these patients; now they know that it does not spread by ordinary touch, they are not scared

Nursing supervisor

The scare that used to be earlier is gone. About three or four years back, we had an HIV-positive patient who had come for treatment to our department. The ward staff sprayed DDT (a pesticide) all around the patient's bed so that the virus would not spread. Now these things do not happen. Now if you go and tell my staff that you are HIV-positive, then they will not even lift their eyes and look at you.

Doctor, Head of department

In terms of their roles in the hospital environment, after the intervention more nurses and ward staff better understood that they could not contract HIV infection as a result of a patient's blood splashing on their own intact skin. Furthermore, at endline a significantly greater proportion of ward staff correctly mentioned that they were at minimal risk of contracting HIV by serving food (91 percent vs. 99 percent) or by coming close to an HIV-positive patient (81 percent vs. 98 percent). 
Table 6 Changes in HIV transmission knowledge (\% correct)

\begin{tabular}{|c|c|c|c|c|c|c|}
\hline & \multicolumn{2}{|c|}{ Doctors } & \multicolumn{2}{|c|}{ Nurses } & \multicolumn{2}{|c|}{ Ward staff } \\
\hline & $\begin{array}{c}\text { Baseline } \\
n=134 \\
(\%)\end{array}$ & $\begin{array}{c}\text { Endline } \\
n=135 \\
(\%)\end{array}$ & $\begin{array}{c}\text { Baseline } \\
n=375 \\
(\%)\end{array}$ & $\begin{array}{c}\text { Endline } \\
\mathrm{n}=375 \\
(\%)\end{array}$ & $\begin{array}{c}\text { Baseline } \\
n=375 \\
(\%)\end{array}$ & $\begin{array}{c}\text { Endline } \\
\mathrm{n}=375 \\
(\%)\end{array}$ \\
\hline \multicolumn{7}{|l|}{$\begin{array}{l}\text { In general, HIV can not be } \\
\text { transmitted by }\end{array}$} \\
\hline Touching PLHA & 98 & 99 & 99 & 99 & 81 & $96^{*}$ \\
\hline Breath of PLHA & 98 & 99 & 99 & 98 & 64 & $76^{*}$ \\
\hline Through sputum & 68 & $50 *$ & 62 & $74^{*}$ & 45 & $51^{*}$ \\
\hline Sharing clothes & 96 & 93 & 86 & $94^{*}$ & 63 & $86^{*}$ \\
\hline Mosquito bites & 81 & 81 & 77 & 82 & 40 & $35^{*}$ \\
\hline Sharing utensils & 95 & 96 & 90 & 93 & 67 & $83^{*}$ \\
\hline \multicolumn{7}{|l|}{$\begin{array}{l}\text { In the hospital setting, HIV } \\
\text { can not be transmitted by }\end{array}$} \\
\hline Handling blood with gloves & 84 & 85 & 95 & 95 & 88 & $97^{*}$ \\
\hline Blood splash on intact skin & 89 & 90 & 88 & $93^{*}$ & 49 & $73^{*}$ \\
\hline Serving food to PLHA & 99 & 100 & 99 & 99 & 91 & $99 *$ \\
\hline Coming close to PLHA & 100 & 100 & 99 & 99 & 81 & $98^{*}$ \\
\hline
\end{tabular}

${ }^{*} \mathrm{p}<.05$

Important strides were also made by HCWs in their understanding of the "window period" following HIV testing. At endline, a greater majority of doctors (94 percent vs. 97 percent) and nurses (82 percent vs. 87 percent) agreed that "a person who tests HIV-negative can still be HIV-positive.” Despite the significant improvements made by ward staff in understanding this concept (14 percent vs. 28 percent), it is clear that a lot of work is still required to enhance their knowledge on this topic.

Also, for some knowledge questions, the proportion answering correctly remained stagnant or declined. For example, at endline fewer doctors (68 percent vs. 50 percent) responded correctly that HIV was not transmitted through sputum. Similarly, fewer ward staff (40 percent vs. 35 percent) correctly reported that mosquitoes were not vectors for transmitting HIV.

\section{Changes in Health Care Workers' Practices}

This section of the report presents data on HCWs' individual practices and perceptions of departmentwide practices related to providing care to HIV-positive patients. The qualitative and quantitative data are presented according to the four key domains of the Checklist: access to services, counseling and testing, confidentiality, and infection control. Some findings are reported separately for each staff cadre while others are reported for all respondents. 


\section{Hgrizons}

\section{Caring for HIV-positive patients}

As shown in Figure 5, the number of doctors, nurses, and ward staff who reported that they cared for or treated an HIV-positive person significantly increased from baseline to endline. When asked about treating a patient with asymptomatic HIV infection, the proportion of doctors who did so increased significantly from 31 percent to 58 percent. There was also an increase in the proportion of doctors who reported feeling comfortable in providing prophylactic care to an HIV-positive patient (50 percent vs. 93 percent).

\section{Figure 5 Change in percent of health care workers ever treating/caring for an HIV-positive patient}

Baseline $\square$ Endline

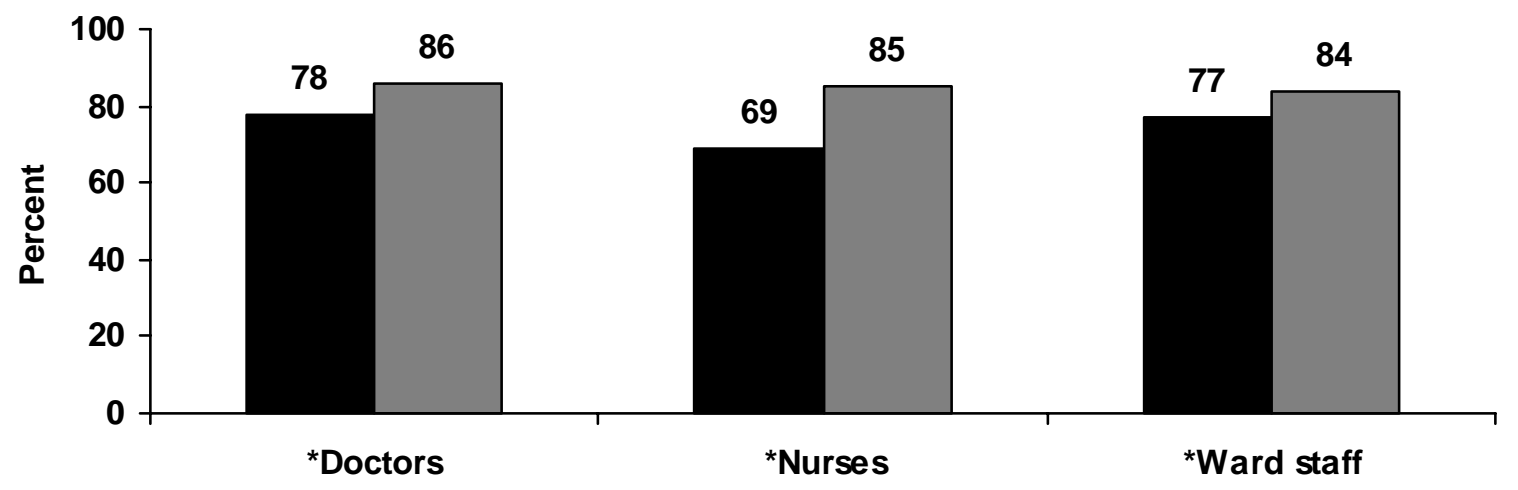

${ }^{\star} \mathrm{p}<.05$

When asked if health care workers had the right to refuse to treat or care for PLHA, very few nurses said they did at baseline and endline. There was a slight decrease among ward staff who thought this, from 11 percent to 6 percent. However, more than a fourth of doctors at both points in time (27 percent and 30 percent, respectively) agreed with this statement. Overall, hospital managers said during the follow-up assessment that refusals of PLHA were rare or non-existent.

No refusals of admission ever. I never refuse HIV cases. One of the NGOs brought a woman here as no other hospital accepted her but when they came to me I took her in. I admit and treat HIVpositive patients in my department.

Doctor, Head of department

Improvements in HCWs' awareness of services for PLHA and other patients increased. At baseline, less than half the doctors, nurses, and ward staff were aware of the availability of a patient grievance cell in their hospital for providing counseling and support to patients. This proportion increased significantly at endline with almost three-fourths of doctors and nurses and over one-half of the ward staff reporting they were aware of these services in their hospital. In addition, the proportion of doctors who were aware of NGOs providing care and support to PLHA increased five-fold (10 percent vs. 49 percent; $\mathrm{p}<.05$ ). 


\section{HIV counseling and testing}

Seeking informed consent is an important component of service delivery. Counseling and testing policies and procedures reflect the way in which PLHA are viewed and treated in a clinical setting. Because doctors are the ones who prescribe HIV tests to their patients, questions on counseling and testing practices and attitudes were posed only to them. At baseline, only about a third of all doctors agreed that a patient's blood should not be tested for HIV without their consent. Of the 77 doctors ( 57 percent) who reported having referred a patient for an HIV test, only 40 percent said they obtained informed consent from the patient prior to the HIV test (Table 7).

Following the intervention, there were marked changes in doctors' attitudes and practices regarding informed consent for HIV testing. The proportion of doctors who agreed that a patient's blood should never be tested for HIV without their consent increased significantly from 37 percent at baseline to 67 percent at endline $(\mathrm{p}<.05)$. Similarly, at endline of the 100 doctors $(74$ percent $)$ who reported they referred patients for an HIV test, there was a significant increase in the proportion who reported having sought informed consent the last time they ordered a test and in the proportion who reported always doing so (Table 7).

Table 7 Changes in doctors' practices on informed consent

\begin{tabular}{|c|c|c|c|}
\hline & $\begin{array}{c}\text { Baseline } \\
\begin{array}{c}n=77^{\star *} \\
(\%)\end{array}\end{array}$ & $\begin{array}{l}\text { Endline } \\
\begin{array}{c}n=100^{* *} \\
(\%)\end{array}\end{array}$ & Significance \\
\hline $\begin{array}{l}\text { Sought informed consent from patient last time } \\
\text { ordered HIV test }\end{array}$ & 40 & 59 & * \\
\hline $\begin{array}{l}\text { Always seek informed consent from patient prior to HIV } \\
\text { test }\end{array}$ & 33 & 53 & * \\
\hline
\end{tabular}

National HIV testing and counseling guidelines issued by NACO specify that all patients should be informed of their HIV test result, whether positive or negative. As shown in Figure 6, of the doctors who had ever ordered an HIV test at baseline, only a third reported they always informed the patient of an HIV-negative test result and only about half reported always informing patients of an HIV-positive test result.

Reported communication of test results by doctors improved following the intervention. At endline, there was a slight increase in the proportion of doctors who informed a patient of an HIV-negative test result as well as HIV-positive test result the last time they referred them for an HIV test. In addition, there was a significant $(\mathrm{p}<.05)$ increase in the number of doctors who reported they always informed their patients of an HIV-negative result (35 percent vs. 54 percent) and an HIV-positive test result (54 percent vs. 85 percent). 


\section{Hgrizons}

Figure 6 Changes in percent of doctors who inform patients of HIV test results

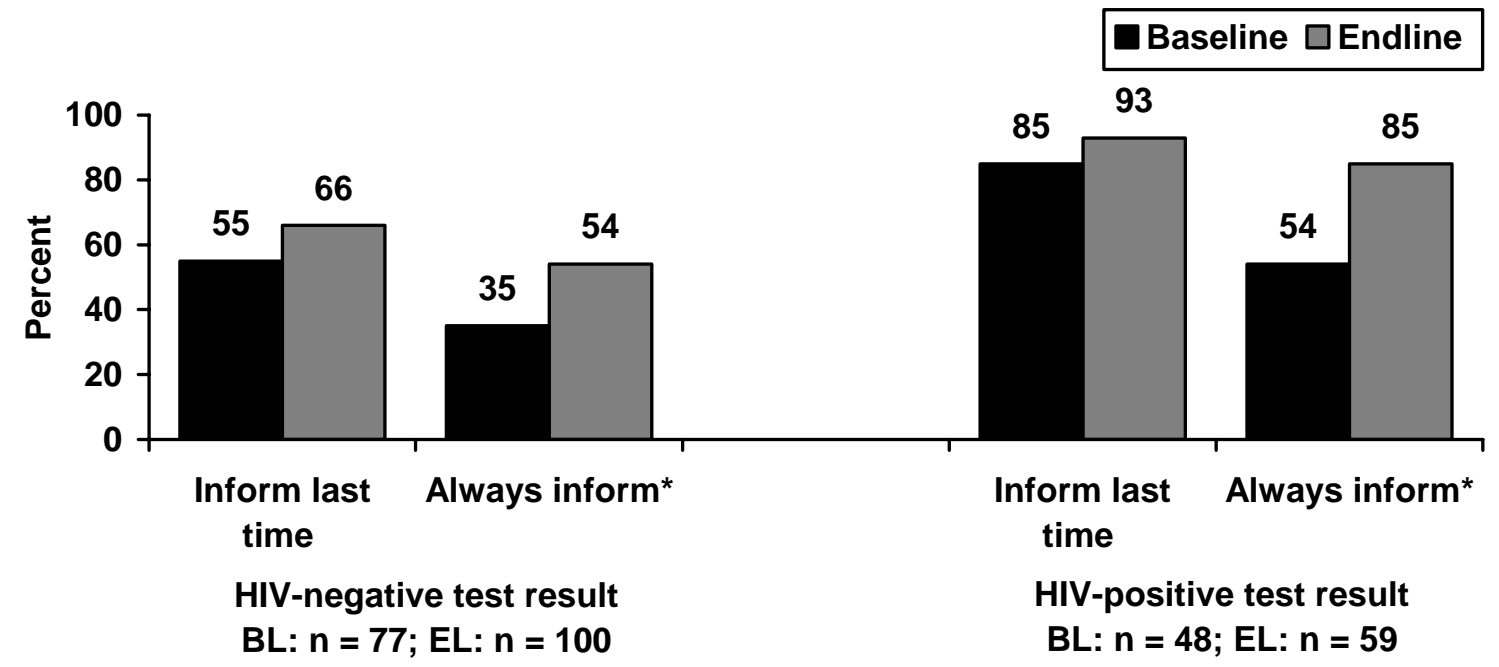

${ }^{*} \mathrm{p}<.05$

A sub-sample of doctors who had ever received a positive test result for a patient ( $\mathrm{n}=48$ at baseline and $\mathrm{n}=59$ at endline) were asked specifically about their practices relating to counseling. At endline, there was a significant improvement in doctors' observation of good counseling practices (Table 8). For example, a significantly $(\mathrm{p}<.05)$ greater proportion of doctors reported that they always arranged pre-test counseling (31 percent vs. 46 percent) and post-test counseling (56 percent vs. 69 percent).

Table 8 Changes in counseling-related practices among doctors

\begin{tabular}{lccc}
\hline HIV counseling and testing & $\begin{array}{c}\text { Baseline } \\
\mathbf{n = 4 8} \\
(\mathbf{4})\end{array}$ & $\begin{array}{c}\text { Endline } \\
\mathbf{n = 5 9} \\
(\mathbf{\%})\end{array}$ & Significance \\
\hline Always arrange pre-test counseling & 31 & 46 & $*$ \\
Always arrange post-test counseling & 56 & 69 & $*$ \\
$\begin{array}{l}\text { Always arrange both pre-test and post-test counseling for } \\
\text { patients }\end{array}$ & 56 & 80 & $*$ \\
\hline
\end{tabular}

${ }^{*} \mathrm{p}<.05$

\section{Confidentiality}

Patients in general and PLHA in particular have a right to confidentiality with respect to their health status. This means that health care workers should not disclose a patient's HIV status without his/her consent, except to other practitioners actively involved in treating the patient. After the intervention, the right of PLHA to decide who should know their status was supported by a greater number of doctors (74 
percent vs. 85 percent; $\mathrm{p}<.05$ ) and nurses (89 percent vs. 92 percent), but not by ward staff (73 percent vs. 66 percent).

At baseline it was found that health care workers often took it upon themselves to inform their peers and other staff in their hospital about an HIV-infected patient's status. However, follow-up assessment shows significantly fewer doctors reported informing nurses (87 percent vs. 71 percent) and ward staff (51 percent vs. 30 percent) about a patient's positive status. Nurses corroborated a change in this practice; at endline fewer reported being informed by doctors of an HIV-positive patient's status who was admitted to their department (31 percent vs. 17 percent). At the same time, the nurses and ward staff did not appear to have become more discreet post-intervention.

Post-intervention, more doctors also agreed that PLHA have the right to decide whether their relatives should be informed of their HIV-positive test result (67 percent vs. 79 percent; $p<.05$ ). Also, when doctors were asked who is usually first informed of the test result, at endline more than half (56 percent) reported that patients were informed first (as opposed to the family) compared to one-third (34 percent) at baseline $(\mathrm{p}<.05)$. When doctors were asked how often they seek consent from patients to disclose a positive test result to the family, there was a significant $(\mathrm{p}<.05)$ positive change in doctors' practices; those reporting "always" increased from 13 percent to 32 percent and "never" dropped by almost half (Figure 7).

\section{Figure 7 Change in doctors' reported frequency of seeking patients' consent prior to disclosure of an HIV-positive test result to the family}

- Baseline $\square$ Endline

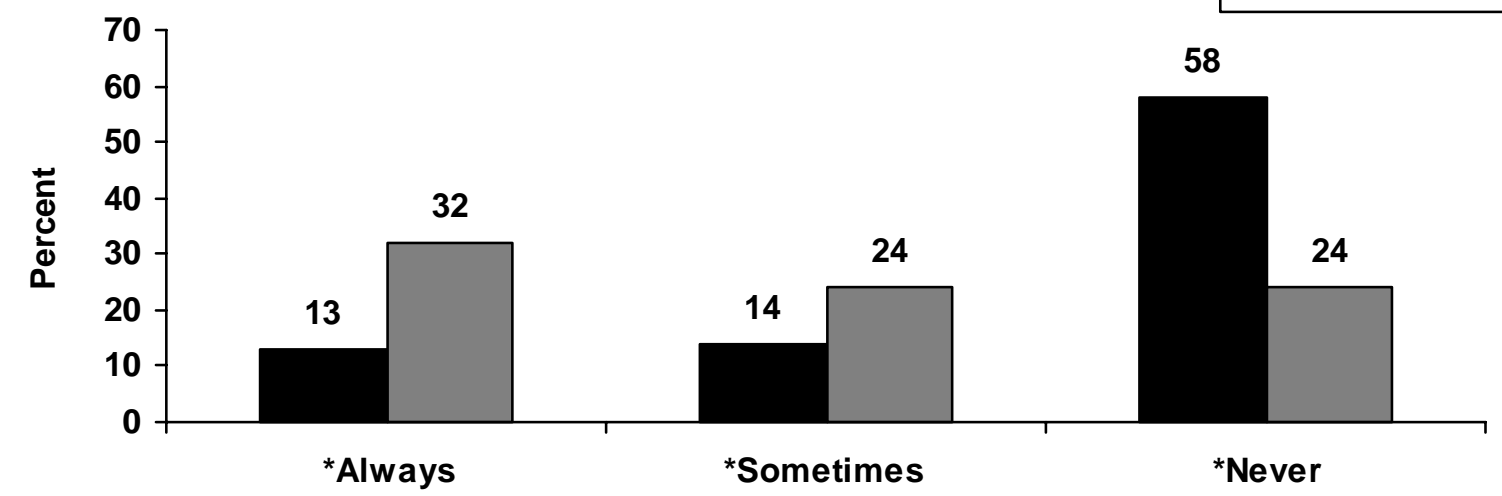

${ }^{*} \mathrm{p}<.05$

However, when doctors were asked about their practices regarding disclosure of test results to a patient's family the last time they received a positive test result ( $n=48$ at baseline and $n=59$ at endline), there was an increase in the proportion that informed family members (from 58 percent (28/48) to 65 percent (38/59)) at endline. And of those, more doctors reported doing so without consent (57 percent vs. 71 percent) as well as informing the family of the test result first (37 percent vs. 53 percent) and not the patient (59 percent vs. 32 percent). Although these changes in reported practice were not statistically significant, they suggest that attitudinal improvements do not always coincide with changes in practice. 


\section{Hgrizons}

As nursing staff are the ones most in contact with patients, they were asked if HIV-positive patients were segregated from others in their department, a procedure that can compromise the patient's confidentiality. At baseline, close to half (43 percent) of the nurses reported the segregation of patients in their department because of their HIV status. At endline, this figure had significantly decreased to 29 percent $(\mathrm{p}<.05)$. This change in practice of segregating patients may reflect a change in staff attitudes; at endline a significantly greater proportion of nurses disagreed with the statement that HIV-positive patients should be segregated from other patients $(\mathrm{p}<.05)$ (Figure 8$)$.

\section{Figure 8 Change in percent of health care workers who disagree that HIV-positive patients should be segregated from other patients in the hospital}

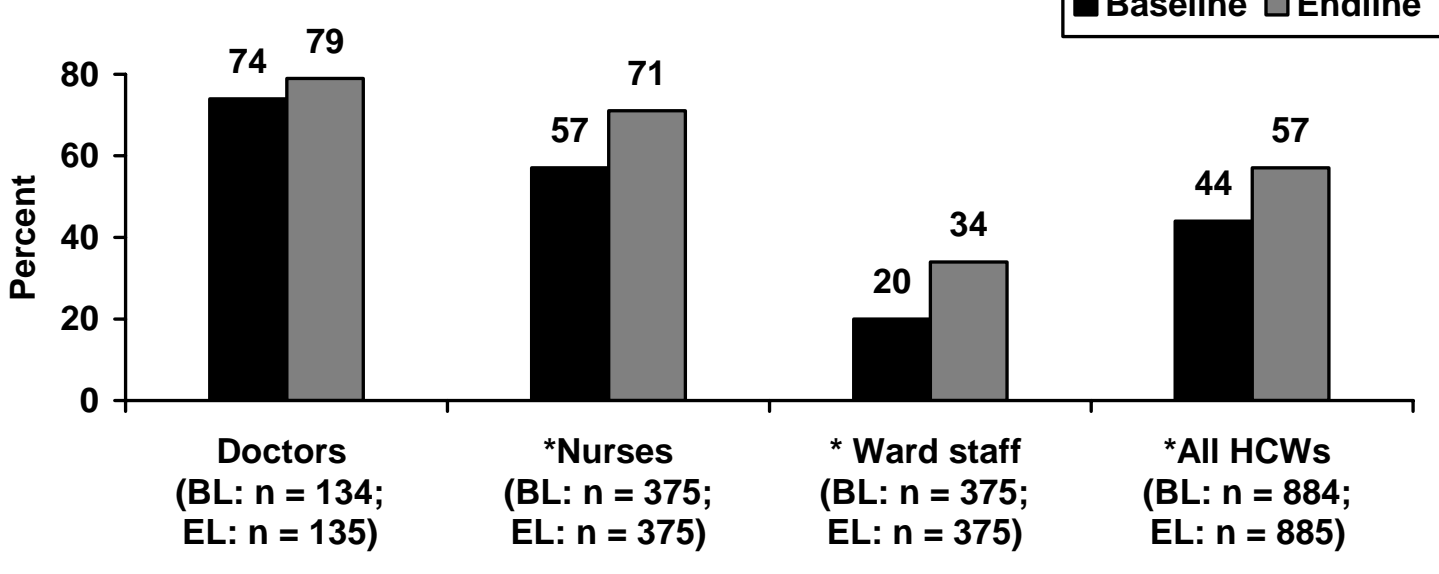

${ }^{*} \mathrm{p}<.05$

In addition, baseline findings indicated that a patient's confidentiality was also breached by the use of labels or bed signs proclaiming his/her HIV status. Although doctors did not report any significant change in this practice, nurses reported a decrease in the labeling of files (91percent vs. 82 percent; $\mathrm{p}<.05$ ). Ward staff corroborated this decrease in marking files; at endline fewer reported acquiring information about a patient's positive status from file markings (15 percent vs. 3 percent; $p<.05$ ). At one of the study hospitals, the head nurse reported that the practice of labeling files and widely sharing patients' HIV status had stopped or reduced considerably even though some of the doctors were not supportive of this change.

Earlier there was a practice to put emblem, stickers on the outside of files of the HIV-positive patients but now we have stopped putting the emblems. We also used to tell positive status of the patient to all staff - there was no confidentiality at all. But, now we are very careful about thiswe have stopped labeling and telling other staff. However, some doctors still feel that there should not be any confidentiality, and object to the whole idea.

Nursing supervisor 


\section{Universal Precautions}

The practice of universal precautions for infection control enables health care workers to handle all patients in a similar manner. If universal precautions are being practiced, no additional, different, or extreme procedures should be needed when handling patients with HIV or other infectious diseases. However, formative research findings indicated that health care workers often practiced "universal" precautions only with patients they knew were HIV-positive or suspected to be infected. The baseline data also corroborated the use of additional precautions by staff when handling patients known to be HIVpositive.

In this section, we first present findings related to glove use, which is one of the most commonly practiced forms of universal precautions, and then we discuss the practice of other infection control procedures.

\section{Glove use}

Data from the baseline survey indicated inappropriate use of gloves by doctors and ward staff. For example, less than two-thirds of doctors reported always using gloves with patients of unknown status for such at-risk procedures as starting an IV (63 percent) or drawing blood (64 percent). But when it came to the same procedures with a patient of known HIV status, almost all the doctors reported using gloves. As shown in Table 9, glove use appears to have changed at endline, suggesting that HCWs learned to practice universal precautions in response to procedures rather than the patient's HIV status.

Table 9 Changes in doctors' use of gloves for at-risk procedures by patient status

\begin{tabular}{lcccc}
\hline $\begin{array}{l}\text { Always wear gloves for the } \\
\text { following procedures: }\end{array}$ & \multicolumn{2}{c}{$\begin{array}{c}\text { With patients of } \\
\text { unknown status }\end{array}$} & \multicolumn{2}{c}{$\begin{array}{c}\text { With HIV-positive } \\
\text { patients }\end{array}$} \\
& BL ( \% ) & EL ( \%) & BL ( \%) & EL ( \%) \\
\hline Draw blood & 64 & $93^{*}$ & 100 & 100 \\
Start an IV & 63 & $85^{*}$ & 100 & 100 \\
Dress wounds & 89 & $94^{*}$ & 100 & 100 \\
\hline
\end{tabular}

${ }^{*} \mathrm{p}<.05$

Even nursing staff, who reported very high use of gloves at baseline for at-risk procedures with patients of unknown status, improved their practice of universal precautions even further. For example, at baseline, 91 percent reported always using gloves to start an IV, 95 percent for drawing blood, and 98 percent to sponge a patient. At endline, 100 percent of the nurses reported they always used gloves for these procedures with patients of unknown status.

There was also a substantial increase in the use of gloves for various at-risk procedures performed by ward staff (Table 10). For example, at baseline less than a third did not wear gloves when carrying blood 


\section{Hgrizons}

samples of patients of unknown status. At endline, the proportion of ward staff who reported always wearing gloves when undertaking this procedure increased three-fold (29 percent vs. 93 percent; $\mathrm{p}<.05$ ).

Table 10 Changes in use of gloves by ward staff

\begin{tabular}{lccc}
\hline & $\begin{array}{c}\text { Baseline } \\
\mathbf{n = 3 7 5} \\
(\mathbf{\%})\end{array}$ & $\begin{array}{c}\text { Endline } \\
\mathbf{n = 3 7 5} \\
(\mathbf{\%})\end{array}$ & Significance \\
\hline Carrying patient's blood samples & 29 & 93 & $*$ \\
Cleaning near patient's bed & 66 & 99 & $*$ \\
Segregating waste in wards & 83 & 99 & $*$ \\
Handling blood-soaked linen & 89 & 99 & $*$ \\
\hline
\end{tabular}

$* p<.05$

\section{Other infection control procedures}

Staff were also asked about their practice of other infection control procedures, such as waste disposal. Doctors and nurses were asked about steps for disposing of used needles and syringes. The reported use of correct methods of waste disposal increased at endline. For example, more staff reported use of a needle destroyer (doctors: 37 percent vs. 69 percent, $\mathrm{p}<.05$; nurses: 75 percent vs. 87 percent, $\mathrm{p}<.05$ ) and a puncture proof container (doctors: 6 percent vs. 21percent; nurses: 20 percent vs. 30 percent) for disposing used needles. Fewer staff reported following the incorrect practice of throwing used needles and syringes in a plastic bag (doctors: 29 percent vs. 3 percent, $\mathrm{p}<.05$; nurses: 18 percent vs. 8 percent, $\mathrm{p}<.05$ ). Similarly, more nurses and ward staff reported correct steps for handling blood-soaked linen. At endline, fewer nurses $(24$ percent vs. 5 percent; $\mathrm{p}<.05)$ and ward staff (18 percent vs. 6 percent; $\mathrm{p}<.05)$ mentioned destroying blood-soaked linen from HIV-positive patients. Post-intervention, staff attitudes tended to reflect improved practices; fewer nurses (67 percent vs. 40 percent; $\mathrm{p}<.05$ ) and ward staff (75 percent vs. 67 percent; $\mathrm{p}<.05$ ) agreed with the need to use such excessive precautions as disposing or burning clothes and linen used by HIV-positive patients.

These improvements in the use of universal precautions may reflect fewer health care workers reporting shortages of gloves and waste management supplies at endline compared to baseline (20 percent vs. 6 percent; $\mathrm{p}<.05$ ). In addition, more health care workers stated that they had access to post-exposure prophylaxis (PEP) at endline compared to baseline (Figure 9). Interestingly, more ward staff reported they had access to PEP post-intervention compared to nurses. 
Figure 9 Change in access to post-exposure prophylaxis (PEP)

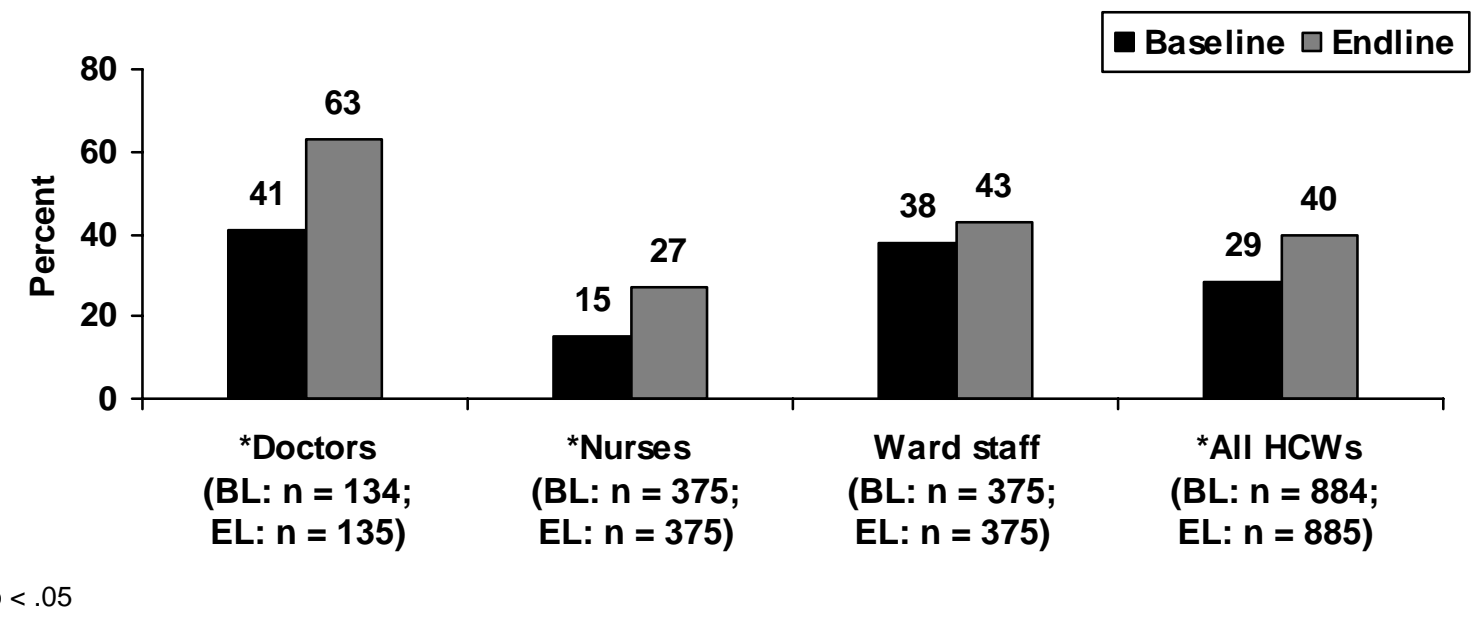

\section{Managers' Perspectives on the I ntervention Process and I mpact}

Following the intervention, researchers interviewed hospital managers and supervisors to gain insights into their perspectives about the intervention and its effectiveness in improving their staff's attitudes and practices regarding the care of HIV-positive patients. It is interesting to note that all 24 respondents interviewed, which included medical superintendents, hospital directors, department heads, and nursing and ward staff supervisors, gave positive feedback about the study process and the intervention and its impact.

According to some of the hospital managers, being involved in a research project was very beneficial. They noted that they became aware of national and international norms of HIV care and management, which gave them the opportunity to evaluate their health care setting in relation to these norms. Moreover, these hospital managers viewed the data on stigmatizing and discriminating attitudes and practices of their health care workers as critical in helping them first to recognize that patients were treated differentially in their hospitals because of their disease status, and secondly, to galvanize them to address this problem.

The research helped us to get on our toes and acts as a quality control tool. This study has brought into light our flaws and also shown us the direction to take to rectify these flaws and help us in this process of rectification too.

Doctor, Head of department

It [the research collaboration] has been a good experience as firstly it has helped us to know what is happening in the outside world, secondly it has led to the hospital giving the subject/ issue its necessary importance, and lastly this has increased the sensitivity among the core group members making them a confident lot.

Medical superintendent 


\section{Hgrizons}

One of the hospital mangers, who was skeptical of the research study in the beginning, came to appreciate the participatory process of designing and implementing the study and intervention.

Initially when you people came in the kind of impression that we had was that of a policeman coming in to someone else's territory and rectifying errors by pointing them out. This caused a little worry among the HODs and therefore you had to face difficulties. But with the efforts you all put into working with us on all aspects of the work it became clear that it is not the case and I feel that this collaboration should not end here-we should have an ongoing relationship.

Doctor, Head of department

Overall, the respondents interviewed were very appreciative of the intervention tools developed for the study, such as the Hospital Guidelines and IEC posters on universal precautions. Even the sensitization training of health care workers was seen as very useful for improving staff attitudes.

There have been positive changes such as development of policies on "No mandatory testing;" counseling, infection control, and universal precautions coming into place; and their implementation. These are steps in the right direction.

Medical superintendent

The policy/guidelines drafted by the project address all the issues, which is of interest to the HCWs for their benefit.

Medical superintendent

The posters were very effective and helped the staff. It helps to reinforce what we doctors try to drum into the staff regularly.

Doctor, Head of department

The training that was given to our ward staff through this project was really useful. A lot of staff, particularly ward staff have been trained and it was of good value. There should be mass training programs at regular intervals for our department-for OT staff, bearers, and lab technicians.

Ward staff supervisor

Some respondents mentioned that the hospital guidelines and IEC materials were used to train all hospital staff (beyond the four study departments) on ethical care and management of HIV/AIDS as well as on infection control procedures.

We have implemented the guidelines and they are used during the in house training sessions of the nurses, ward staff, and paramedic staff. These have been put all over the hospital in all the nursing stations/wards/operation theaters/out-patient departments.

Medical superintendent

The posters are very effective and helped the staff. Now when new staff, especially junior doctors, join, along with the lectures we just ask them to follow the posters.

Doctor, Head of the Department 
We have trainings for our staff regularly and we have included the posters and guidelines as part of our internal training programs.

Nursing supervisor

When the respondents were asked about the impact of the intervention on their hospital, a majority of them felt that there was improvement in health care workers' attitudes and practices, including their own.

Improvement is there. There has been a definite decline in stigma associated with the disease, as there has been a decline in the level of fear associated with this disease.

Doctor, Head of department

Earlier I thought that all HIV tests should be mandatory but now after your work I realize that universal precautions is the key and HIV tests should not be mandatory.

Doctor, Head of department

Most respondents felt that they could now describe their hospital as "PLHA-friendly."

Yes, this is HIV-positive patient friendly. Patients are lying next to each other. Other patients do not know about each other's disease. No one is refused care and treatment in this hospital.

Nursing supervisor

Yes, it is a patient friendly hospital and you have played a very important role, I should say excellent role, in our hospitals development.

Medical superintendent

However, there were a few who felt they needed to work harder to reduce stigma and discrimination before they could categorize their hospital in this way.

The situation has improved a lot but I cannot exactly say that it is patient friendly as yet... we are talking about the need to still go through a series of processes to be done by a whole lot of human beings. We are trying to do the best we can with the available resources.

Doctor, Head of department

We are only 50 percent friendly. We are not optimally friendly with the positive patients. We are trying to fight with this stigma. There needs to be more teamwork; we need more social workers and better counseling facilities in our hospital.

Doctor, Head of department 


\section{Hgrizons}

\section{Conclusion and Recommendations}

The formative research findings clearly indicated the need to address stigma and discrimination in the hospital setting and corroborated many of the findings of earlier research in India in this context (UNAIDS 2001). This study found that although HCWs generally denied that their hospital refused admission and/or treatment to patients because of their known or suspected HIV status, caregivers and patients reported that the access to and quality of in-patient care in New Delhi hospitals depended on a patient's HIV status. Experiences with and fears about such treatment was enough to deter some patients from seeking care, and cause other patients to conceal their HIV-status from HCWs, if possible.

Common manifestations of differential treatment of PLHA in the participating hospitals included delay in treatment, unwarranted referrals to other facilities, segregation, labeling, excessive use of barrier precautions, breaches of confidentiality, unconsented HIV-testing, inadequate pre-and post-test counseling, and withholding HIV test results from patients. The study also found that many health care workers lacked adequate knowledge and training in the basics of HIV transmission, infection control, and clinical management of HIV/AIDS. Also, a lack of hospital policies protecting PLHA and ensuring staff safety contributed to differential treatment.

These findings highlight that stigma and discrimination in health settings is fueled by both individual and institutional factors. Therefore, reducing AIDS-related stigma and discrimination in clinical settings requires addressing not just the attitudes and practices of health care workers but also their needs for information, training, and supplies.

The study also showed that all cadres of health care workers, including doctors, nurses, and ward staff, carry out discriminatory practices. It was interesting to note that even though ward staff are not engaged in providing clinical care to patients, they still had the most discriminatory attitudes toward PLHA. Because of the important role they play in providing support services in the hospital, it was critical for the intervention to target ward staff. This supports the intervention's basic premise of involving all levels of health care workers, from ward staff to hospital superintendents, in improving the hospital environment rather than simply trying to effect change from the top down by only working with management.

The participatory methods used by the project team proved to be crucial in mobilizing hospital managers to take action to reduce stigma and discrimination. Facility-specific survey data, the checklist, and other tools sparked action among managers to make the hospitals more "PLHA-friendly" and facilitated ownership of the process. The hospital managers were engaged in designing and implementing the multilevel intervention that included training, materials development, and policy reform.

Although the study design does not allow the researchers to definitively prove the efficacy of the approach, pre- and post-survey data show significant improvements in health care workers' reported knowledge, attitudes, and practices related to the care and management of PLHA. Interviews with hospital managers corroborated many of the changes detected by the quantitative data. But, despite these positive findings, there is room for fine-tuning of the intervention. The study demonstrated that some attitudes and practices may be more difficult to change than others and may require more focused activities. For example, support for mandatory testing for invasive procedures was about the same after the intervention. This lack of change in HCWs' attitudes toward testing may be due to their heightened 
risk perception of contracting HIV from their patients. To allay these fears, hospitals may need to place a greater focus on improving HCWs' access to appropriate infection control methods and the use of universal precautions. Also, the meaning, norms, and values placed upon seemingly universal principles like patient confidentiality may in fact differ in different settings. For example, in this setting, while there was improved respect for patient privacy in general, many HCWs continued to feel that they were entitled to know the HIV status of their patients and continued to share such information with one another. Therefore, more work is needed to translate changes in attitudes and beliefs to changes in practice.

Even in large public hospitals confronting a wide range of institutional challenges, it is possible to create positive change. This study demonstrates that government, private/non-profit, and research groups each have a role to play in reducing stigma and discrimination in the health sector. However, a respectful and open attitude on the part of each sector is required for such a partnership to succeed. For example, when the intervention began, hospital managers feared that data about stigma and discrimination would be used for lawsuits and negative publicity, and AIDS NGOs tended to blame health care workers for stigmatizing or discriminatory practices. In response, the study team reassured the hospitals that the data would be confidential and not be reported by hospital, and sensitized AIDS NGO staff about the concerns and difficulties of health care workers who practice in overburdened, resource-constrained settings.

In sum, the following recommendations emerged from the study:

\section{In order to reduce stigma and discrimination, it is important to assess and improve HIV/AIDS-related knowledge and attitudes of all HCWs.}

Misinformation and judgmental attitudes among all cadres of HCWs can foster stigma, fear, and differential treatment of PLHA. This study showed that even the most senior HCWs do not have complete understanding of HIV transmission and prevention. Therefore, it is important for programs to target all levels of HCWs with initial and ongoing refresher training. Such training should go beyond providing information to include sensitizing staff to the needs, concerns, and rights of PLHA.

\section{Efforts to increase knowledge and improve attitudes must be accompanied by policies, information, and supplies that create a safe working environment for HCWs.}

This and other studies (Nyblade et al. 2003) have shown that health care workers perceive themselves to be at high risk of infection because of their exposure to the virus during service delivery. Thus, training alone may not have the desired impact on health care workers' attitudes and practices if they do not perceive environment within which they work to be safe to implement their newly acquired knowledge and skills. Thus it is essential to assess and acknowledge health care workers' fears and risk and then develop and implement workplace policies that ensure staff safety and respect for health care workers rights. These policies need to ensure the availability of essential supplies (e.g., gloves, post-exposure prophylaxis) for maintaining optimum infection control practices by health care workers at all times to not only protect themselves but also to protect their patients from exposure to infection. 


\section{Hgrizons}

\section{A multi-sectoral, participatory approach to reducing stigma and discrimination is promising.}

The improvements in reported HCW attitudes and practices and in hospital policies support an approach characterized by participatory problem identification and problem solving, and the involvement of all levels of staff in intervention activities, from ward staff to hospital superintendents. Groups and organizations wishing to work in health care settings should consider positioning themselves as true partners rather than as critics or watchdogs/whistle blowers if their goal is to improve the health care environment for PLHA.

\section{Further research is needed to determine whether the improvements observed reflect actual reductions in stigma and discrimination as perceived by PLHA.}

Conducting this research in Indian hospitals that now are seeing greater numbers of PLHA or in regions with a higher HIV prevalence would enable researchers to gain valuable feedback from HIV-positive patients. Also, any further research should examine the role of increased availability of antiretrovirals on stigma and discrimination in health care settings. 


\section{Utilization of Research Results and Tools}

The results of the study galvanized the collaborating New Delhi hospitals to scale up the intervention hospital-wide to all departments and staff. In addition, NACO endorsed the use of the "PLHA-friendly Checklist" in all public hospitals, and disseminated it to all the State AIDS Control Societies in the country. One of the country's largest public sector insurance-based health delivery systems - the Employees State Insurance Corporation-requested multiple copies of the Guidelines, IEC materials, and Checklist for use in their hospitals. In addition, some AIDS service NGOs in the country have used the PLHA-friendly Checklist to assess and strengthen their services and the IEC materials to train their staff on infection control procedures. The Population Council's European Commission-funded HIV/STI Prevention and Care Program in India utilized the Checklist in one of their hospital-based research programs as a tool to measure intervention impact. The Christian Medical Association of India (CMAI), which has a membership of over 500 hospitals and 3,000 health care practitioners in the country, has expressed interest to scale up the "PLHA-friendly" intervention in their hospitals.

Globally, UNAIDS featured the study as one of the few hospital-based interventions to counter stigma and discrimination in their report on the global AIDS epidemic (2002) and is also planning to include an update with study results in the 2006 report. The International Council of Nurses, based in Switzerland, endorsed the use of the PLHA-friendly Checklist as an integral part of their Nurses: Fighting AIDS Stigma Caring for All: Information and Action Tool Kit on the occasion of International Nurse Day in 2003. The Muhimbili Health Exchange Forum in Tanzania has posted the Checklist on their internet site for widespread dissemination and use by health care professionals in district level settings in the country. UNAIDS in Nepal is currently reviewing the PLHA-friendly intervention tools to adapt them as part of their stigma reduction tool kit for the country. Finally the study was featured by USAID's Bureau for Global Health as a "success story” in 2003. 


\section{Hgrizons}

\section{References}

Asia Pacific Network of People Living with HIV/AIDS (APN+). 2004. AIDS Discrimination in Asia. Thailand: APN+ Secretariat.

Bharat, S. and P. Aggleton. 1999. "Facing the challenge: Household responses to AIDS in India,” AIDS Care 11:33-46.

Brown, L, K. Macintyre, and L. Trujillo. 2003. "Interventions to reduce HIV/AIDS stigma: What have we learned?” AIDS Education and Prevention 15(1):49-69.

Centre for Advocacy and Research (CFAR), Positive Women's Network (PWN+), and UNIFEM. 2003. Positive Speaking_Voices of Women Living with HIV/AIDS. New Delhi: UNIFEM.

Crandall, C. and D. Moriarty. 1995. Physical illness, stigma and social rejection. British Journal of Psychology 34 (1): 67-83

Goffman, E. 1963. Stigma: Notes on the Management of a Spoiled Identity. New York: Simon and Schuster.

Horizons Program. 2002. "HIV/AIDS-related stigma and discrimination: A conceptual framework and agenda for action,” Horizons Report. Washington, D.C.: Population Council.

Horizons Program, International HIV/AIDS Alliance, and Tata Institute of Social Sciences. 2003. The involvement of people living with HIV/AIDS in the delivery of community-based prevention, care and support services in Maharashtra, India - A diagnostic study. Brighton, U.K.: Population Council, International HIV/AIDS Alliance, and Tata Institute of Social Sciences.

Link, B. and J. Phelan. 2001. "On stigma and its public health implications, ” paper presented at Stigma and Global Health: Developing a Research Agenda, National Institutes of Health, Washington, DC, September 5-7, 2001.

Mann, J. 1987. Statement at an informal briefing on AIDS to the $42^{\text {nd }}$ Session of the United Nations General Assembly, 20 October, New York.

Nyblade, L., et al. 2003. Disentangling HIV and AIDS Stigma in Ethiopia, Tanzania and Zambia. Washington, D.C.: International Center for Research on Women.

Reidpath, D. and K. Chan. 2005. HIV discrimination: integrating the results from a six-country situational analysis in the Asia Pacific. AIDS Care Suppl 2, 195-204.

UNAIDS. 2001. "India: HIV and AIDS-related discrimination, stigmatization and denial," UNAIDS Best Practice Collection, prepared by Shalini Bharat, with Peter J. Aggleton, and Paul Tyrer. Geneva: UNAIDS. 
—. 2002. Report on the Global HIV/AIDS Epidemic. July 2002. Geneva: UNAIDS.

van Brakel, W. H. 2006. "Measuring health related stigma: a literature review," background paper prepared for the International Stigma Workshop at Soesterberg, 2004.

van der Meij, S and M. Heijnders. 2004. "The fight against stigma: Stigma reduction strategies and interventions,” background paper prepared for the International Stigma Workshop at Soesterberg, 2004. 


\section{Hgrizons}

\section{Appendix PLHA-friendly Checklist}

\section{ACCESS TO CARE SERVI CES}

Practice

1. Care for PLHA (or patients awaiting results of an HIV test) is not denied, delayed, or referred elsewhere for services available within the facility.

2. Care for PLHA is of the same quality as the care provided to other patients.

3. PLHA are not segregated or isolated.

4. The hospital actively links PLHA to sources of ongoing palliative care and social support in their own communities.

Training

1. All staff are trained in patients' rights and the right of PLHA to equal care and confidentiality.

Quality Assurance

1. An accessible patient grievance cell, which registers and addresses patient complaints, is in place and open daily.

2. The existence of the grievance cell is posted in each ward and in all patient waiting areas.

Policy

1. Hospital policy guarantees all of the above.

2. Hospital policy on access and right to care is posted in all departments and patient waiting areas.

\section{TESTI NG AND COUNSELI NG}

\section{Practice}

1. All HIV tests are voluntary.

2. All HIV tests are accompanied by informed consent.

3. All HIV tests are accompanied by pre-test counseling by a trained counselor.

4. All test results are communicated to the patient during post-test counseling by a trained counselor.

Training

1. All treating health care workers (HCWs) are trained in principles and procedures of voluntary testing and counseling.

2. HIV test counselors are trained and receive ongoing refresher training.

Quality Assurance

1. A committee is in place that ensures that the above procedures and training are operational. 
Policy

1. Hospital policy guarantees all of the above.

2. Hospital policy on testing and counseling is posted in all departments and patient waiting areas.

\section{CONFI DENTI ALITY}

\section{Practice}

1. Information about HIV status is communicated only to the patient and treating HCWs and is otherwise kept confidential.

2. Information about HIV status is never disclosed to the patient's family or friends, except with the explicit informed consent of the patient.

3. PLHA beds, wards, and files are not labeled in ways that would convey HIV status to other patients or staff.

Training

1. All health care workers are trained in the principles of and patients' rights to confidentiality.

\section{Quality Assurance}

1. A committee is in place that monitors the management of information system to ensure that it adequately protects confidentiality.

Policy

1. Hospital policy guarantees all of the above.

2. Hospital policy on confidentiality is posted in all departments and patient waiting areas.

\section{I NFECTI ON CONTROL}

\section{Practice}

1. Universal precautions are practiced, in the same manner, with all patients at all times.

2. Sound waste management is practiced at all times by all staff.

3. All staff are informed about and provided with free hepatitis vaccines and, if required, postexposure prophylaxis (PEP).

\section{Training}

1. All staff are trained in the basics of HIV and hepatitis transmission and prevention, infection control (including universal precautions or UP), waste management, and PEP.

\section{Quality Assurance}

1. Essential supplies for universal precautions, infection control, and PEP are available at all times to all staff for universal precautions.

2. An infection control team is in place and meets regularly (once a month or more) to monitor infection control practices and supplies. 


\section{Hgrizons}

3. Information, education, and communication (IEC) materials on infection control procedures are posted in all wards and staff areas.

Policy

1. Hospital policy guarantees all of the above.

2. Hospital policy guarantees a safe working environment for all HCWs.

3. Hospital policy on infection control and staff safety is posted in all departments and patient waiting areas.

\section{QUALITY OF CARE}

\section{Practice}

1. PLHA are provided the highest available standard of clinical management and care.

2. Pregnant women are offered, though not compelled to accept, HIV testing, antiretroviral (ARV) treatment to reduce likelihood of mother-to-child transmission of HIV during delivery, and advice on infant feeding.

3. Testing of pregnant women is voluntary and confidential and is accompanied by pre- and posttest counseling.

4. PLHA are offered or referred to advice about nutrition and health-promoting lifestyles.

\section{Training}

1. Clinical staff are regularly trained and re-trained in case management of HIV/AIDS.

Quality Assurance

1. ARVs and/or essential drugs for reducing mother-to-child transmission and treating opportunistic infections (OIs) are consistently stocked and administered.

2. A team is in place to oversee care for PLHA and to track advances in clinical management of HIV/AIDS.

3. Guidelines for HIV/AIDS case management are available in each department.

Policy

1. A policy is in place that guarantees all of the above.

2. The policy is posted in all departments and patient waiting areas. 


\section{Hgrizons}

Horizons is a global operations research program designed to:

- Identify and test potential strategies to improve HIV/AIDS prevention, care, and support programs and service delivery.

- Disseminate best practices and utilize findings with a view toward scaling up successful interventions.

\section{(2) Population Council}

Horizons is implemented by the Population Council in collaboration with

- International Center for Research on Women (ICRW)

- International HIV/AIDS Alliance

- PATH

- Tulane University

- Family Health International (FHI)

- Johns Hopkins University

For more information, please contact:

Horizons Program/Population Council 53 Lodi Estate

New Delhi - 110003, India

Tel: 91-11-24610913/14

Fax: 91-11-24610912

Email: horizons-india@popcouncil.org www.popcouncil.org/horizons 